\title{
XVII.
}

\section{Die Vita propria der Zellen des Periosts.}

(Aus dem pathologischen Institut zu Greifswald.)

Von Dr. B. Grohé.

(Hierzu Taf. XI.)

A) Allgemeines über die Vita propria.

Schon 1852 schreibt Virchow ${ }^{1}$ ): „Jede Zelle ist als solche eine geschlossene Einheit, die in sich selbt den Grund, das Princip ihres Lebens aufgenommen hat, die in sich selbst die Gesetze ihrer Existenz trägt, und die gegenüber der übrigen Welt eine bestimmte Autonomie besitzt. Eine von der Verbindung mit ihrem Mutterkörper losgelöste Zelle ist dadurch noch nicht tot, sondern sie kann noch längere Zeit bindurch eine Reihe der positivsten Lebenserscheinungen darbieten, die niemals wieder an ihr hervorgerufen werden können, sobald sie wirklich abgestorben ist. Ein Theil kann für längere Zeit aus der Nervenverbindung austreten und doch sein Leben conserviren, ja wir sehen, dass sogar Theile, die aus aller Verbindung gelöst waren, ihre Lebensverrichtungen in der ausgedehntesten Weise wieder aufnehmen, ohne dass sie zunächst in eine neue Nervenverbindung eintreten, wenn sie nur in der Lage sind, Ernährungsmaterial zu beziehen."

Diese der einzelnen Zelle zustehende Lebensfähigkeit bezeichnet Virchow an anderer Stelle ${ }^{2}$ ) als die "Vita propria“" der Zelle.

So wichtig für die Beurteilung des Lebensprocesses nun die Thatsache des Fortbestehens des eigenen Lebens der Zelle nach Lostrennung vom Gesammtorganismus ist, so auffallend ist es,

1) Virchow: Ernährungseinheiten und Krankbeitsbeerde. Dieses Arch. 1852. Bd. IV.

2) Virchow: Krankheitswesen und Krankheitsursachen. Dieses Arch. 1880. Bd. 79. 


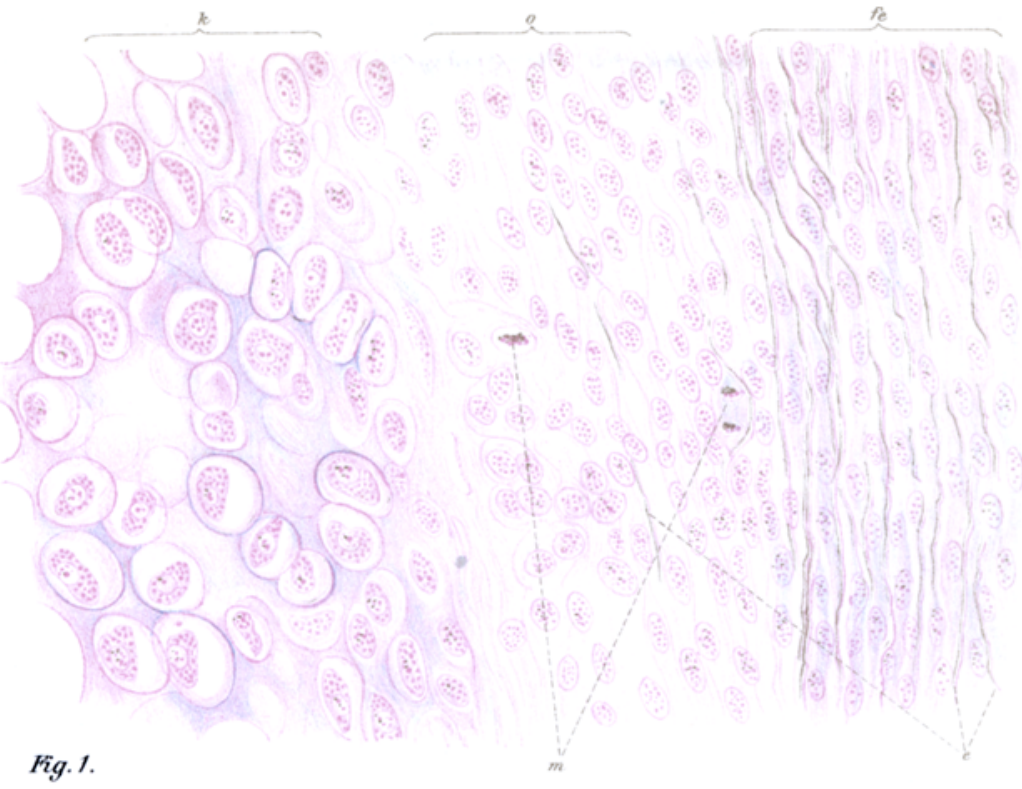

Fig. 2.

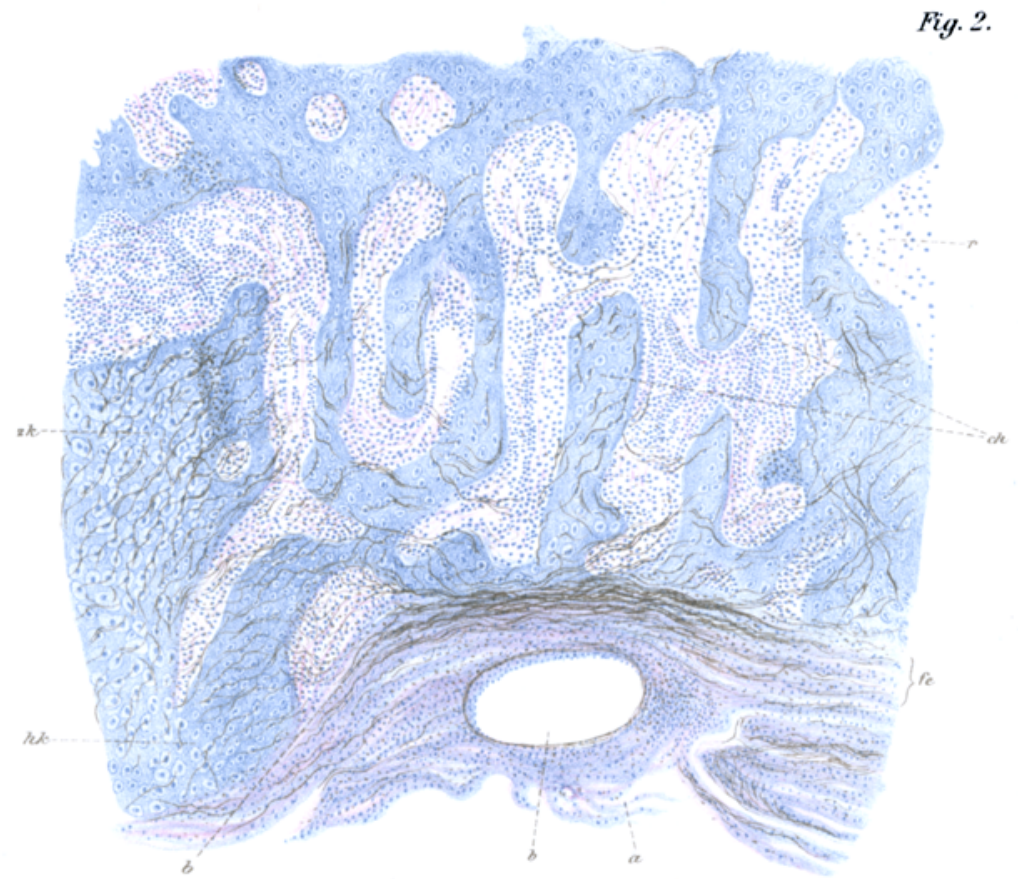


dass über die Intensität und Dauer dieser Lebensfähigkeit keine systematischen Untersuchungen angestellt worden sind.

Nur hier und da verstreut finden sich vereinzelte Notizen, die sich oft nur auf zufällige Nebenbefunde bei anderweitigen Untersuchungen beziehen. Erst in jüngster Zeit hat sich die Aufmerksamkeit dieser Frage wieder zugewandt und zwar ist es Grawitz ${ }^{1}$ ), welcher das Interesse dafür wieder erweckte. Bei seinen Untersuchungen über die Entzündung der Cornea, war Grawitz auf die Thatsache gestossen, dass Schädigungen, welche man a priori für ausreichend gehalten hatte, alles Leben im Hornhautgewebe zu vernichten, absolut nicht diesen Erwartungen entsprachen.

Nach dem Trocknen konnte er durch die Uebertragung der Schweinecornea in die Bauchhöhle des Kaninchens Vergrösserung, Anastomosenbildung und mitotische Kernteilungen in den Hornhautkörperchen in grosser Zahl nachweisen, und an der Hasenhornhaut, in welcher 11 Tage nach dem Tode die Vergoldbarkeit geschwunden war, trat nach dem Einlegen in lebenden Lymphstrom nicht nur die Vergoldbarkeit wieder ein, es kam zu Veränderungen der Hornhautkörperchen, welche denen vollkommen entsprechen, welche man an lebensfrisch transplantirtem Gewebe wahrnimmt.

Daraus folgte, dass der Augenschein für die Beurtheilung der Vita propria nicht massgehend sein konnte, ebensowenig wie vorgefasstes Urteil und Augenschein darüber entscheiden können, ob bei eingetrockneten Tieren, wie den Anguillulae und Tardigraden das Leben auch ohne nachweisbaren Stoffwechsel fortbesteht.

Grawitz gab hiermit die Anregung, nachdem er die Thatsache des Fortbestehens der Vita propria an zahlreichen Beispielen aus der Literatur nachgewiesen hatte ${ }^{1}$ ), nunmehr die Erforschung der näheren Bedingungen für die einzelnen Gewebe in Arbeit za nehmen.

Der Vitalität der Flimmerzellen widmete Busse ${ }^{2}$ ) seine Auf-

1) P. Grawitz: Biologische Studie über die Widerstandsfähigkeit lebender thierischer Gewebe. - Deutsch. med. Wochschr. 1897 No. 1-3.

2) 0. Busse: Ueber das Fortleben losgetrennter Gewebsteile. Dieses Arch. Bd. 149. 1897. 
merksamkeit. An Flimmerepithelien von Polypen aus dem menschlichen Nasenrachenraum sah er noch 18 Tage nach der Loslösung vom Mutterboden die Erhaltung des Lebens und seiner Energie, einmal durch die noch deutlich vorhandene Cilienbewegung, dann durch die Erhaltung der glänzenden (contractilen) Beschaffenheit des Zellleibes. Diese Lebensäusserungen liessen sich zuweilen auch noch in z. T. schon in Fäulniss übergegangenen und halb zerflossenen Praeparaten beobachten; eine Aufbewahrung in kälteren Temperaturen (c. $+4^{\circ}$ C.) erwies sich als die vorteilhafteste für diese Zwecke.

Dass auch die Spermatozoen ihre Eigenbewegung längere Zeit nach dem Tode des Stammthieres oder der Ausschaltung derselben aus dem lebenden Organismus erhalten, konnte Schade ${ }^{1}$ ) beobachten. Noch elf Tage nach der Exstirpation eines Meerschweinchenhodens documentirte sich das Leben der entnommenen Spermatozoen durch ihre deutliche Bewegungsfähigkeit.

Je näher die Temperatur, in welcher die Versuchsobjecte aufbewahrt wurden, dem Gefrierpunkt lag, und zwar in möglichst andauernder Gleichmässigkeit, desto günstigere Resultate wurden erzielt.

Dass die Kenntniss dieser langen Vita propria der Spamatozoen von entschiedenem Werth ist, wird in der genannten Dissertation durch einen forensisch wichtigen Fall beleuchtet, indem die mögliche Existenz der Lebensdauer für die Beurteilung eines Verbrechens von entscheidender Wichtigkeit wurde.

Bei der gerichtlichen Obduction eines ermordeten Knaben fanden sich nehmlich im Rectum Spermamassen, in denen lebende Spermatozoen durch die mikroskopische Untersuchung festgesteslt wurden. Die Leiche hatte acht Tage bei einer Temperatur, welche $z$ wischen $+3^{\circ}$ und $-3^{\circ} \mathrm{C}$. schwankte, im Wasser gelegen. Da die Möglichkeit eines derartigen Befundes in Zweifel gezogen war, der Mörder die Absicht der Päderastie eingestanden, aber dass vollendete Stuprum bestritt, wurde an das patbolog. Institut eine dementsprechende Anfrage gestellt, welche nach den vorliegenden Untersuchungen Schade's positiv beantwortet werden konnte. Nicht nnwichtig ist es, dass der Mörder den Akt schliesslich eingestanden bat, was beim Erscheinen der Schade'schen Arbeit noch nicht der Fall gewesen war, und somit es feststeht, dass im Rectum der Leiche die Beweglichkeit der Spermaiäden acht Tage lang sich erhalten kann.

1) Schade: Biolog. Untersuchungen über die Lebensfähigkeit von ganzen Organismen und einzelnen Zellen. - Inaug.-Diss. Greifswald. 1898. 
Aus dem eben Geschilderten ersehen wir, dass die Dauer des Lebens der verschiedenen Zellen eine oft erstaunlich lange sein kann. Aber nicht nur die reine Vitalität mit den einfacheren Lebensäusserungen, wie Motilität $u$. dergl. bestehen fort, sondern selbst feinere Functionen der Zelle, nehmlich die der Proliferation, bleiben erhalten und zeugen davon, dass die Lebensenergie der einzelnen Zellen erst viel später nach dem Tode des Gesammtorganismus erlischt.

Diese erhaltene Proliferationsmöglichkeit hatte Wentscher ${ }^{1}$ ) bei den Hautepithelien gefunden, indem er beobachtete, dass Thiersch'e Hautläppchen ihre plastischen Eigenschaften behielten, selbst wenn sie 48 Stunden in Kochsalz conservirt wurden.

Durch Grawitz' biologische Studien angeregt, stellte Wentscher erneute Versuche ${ }^{2}$ ) an, welche diesmal direkt die theoretische Frage von der Lebensdauer der Hautepithelien verfolgten.

Die Hautläppchen wurden in steriler Kochsalzlösung oder trocken auf sterilem Gazepolster verschieden lange aufgehoben und dann transplantirt. Von 59 Versuchen sind 30 positiv im biologischen Sinne ausgefallen. Das älteste der mit Erfolg transplantirten Läppchen war 22 Tage alt.

Bei der Erforschung des Verhaltens äusseren (chemischen resp. thermischen) Einflüssen gegenüber, erwiesen sich die Läppchen chemischeu Schädigungen gegenüber als sehr empfindlich. Versuche mit antiseptischen Lösungen verschiedener Art fielen bis auf einen negativ aus.

Bei den Temperaturen schienen böhere Wärmegrade nicht so gut vertragen $\mathrm{zu}$ werden, doch war eine viertelstündige Erwärmung auf $50^{\circ} \mathrm{C}$. in einem Falle nicht im Stande, die vitalen Eigenschaften der Epidermiszellen wesentlich zu beeinträchtigen.

Sehr tolerant erwies sich die Haut aber gegen Kälte. Von einem 14 Stunden lang bei einer Mindesttemperatur von $-5^{\circ} \mathrm{C}$. hartgefrorenen und danach vorsichtig aufgethauten läppchen heilte der weitaus grösste Theil in idealer Weise an.

1) J. Wentscher: Die Verwendung conservirter Hautlappen bei der Transplantation nach Thiersch. - Berl. klin. Woehenschr. 1894. No. 43.

2) J. Wentscher (Thorn): Wie lange und unter welchen Umständen bleibt die Lebensfähigkeit der menschlichen Epidermiszellen ausserhalb des Organismus erhalten? - Centrbl. f. Chir. 1898. No. 1. 
Eine dementsprechende Resistenz gegen intensive Kälte beschreiben übrigens bei sofort vorgenommener Transplantation auch Schnitzler und Ewald ${ }^{1}$ ), die eine Schädigung des Lappens, welcher, durch Aethylchloridsprag fast hart gefroren war, nicht wahrnehmen konnten.

Aehnliche Untersuchungen wie Wentscher stellte auch Ljunggre $n^{2}$ ) an, nur mit dem Unterschied, dass er die Hautläppchen in menschlicher Ascitesflüssigkeit, meist bei Zimmertemperatur aufbewabrte. Er erzielte nach 6 tägiger und 1 wöchentlicher Aufbewahrung eine völlige Regeneration der Epithelien. Als Nebenbefund sei erwähnt, dass er nach 3 monatlichem Aufenthalt der Hauttheile in der sterilen Flüssigkeit noch Kernfärbung in den Geweben erzielte.

Bei einer Nachprüfung der Wentscher'schen Versuche gelangte endlich Enderlen ${ }^{3}$ ) zu Resultaten, welche den beiden eben angeführten in den Erfolgen nicht so gleich kommen.

Er ging in derselben Weise wie Wentscher vor und bewahrte die Hautstücke entweder in steriler Kochsalzlösung oder in sterilen Gefässen auf bei einer mittleren Temperatur (Operationsraum.)

Zweimal und zwar einmal bei einer 24 Stunden alten, noch feuchten Haut, das andere Mal bei einem Hautstück, welches am 4. Tag noch feucht war, fand die Anheilung statt.

Vollkommen trockene Hautstïcke gelangten überhaupt nicht zur Anheilung.

In allen Fällen zeigte das Epithel eine viel grössere Widerstandsfähigkeit gegen schädliche Einflüsse, als die Cutis, welche z. B. am 4. Tage völlig zu Grunde gegangen zu sein schien. Der ganze Regenerationsvorgang spielte sich dem Anschein nach in viel langsamerer Weise $a b$, wie bei normal vorgenommenen Transplantationen.

Die Ergebnisse der Anheilungsversuche zeigen, wie ersicht-

1) J. Schnitzler und E. Ewald: Zur Technik der Hauttransplantation nach Thierseh. - Centralbl. f. Chir. 1894 S. 148.

2) Ljunggren: Von der Fähigkeit des Hautepithels ausserhalb des Organismus sein Leben zu behalten mit Berücksichtigung der Transplantation, - D. Zeitschr. f. Chir. Bd. 47. 5-6. Hft. 1898.

3) Enderlen: Ueber die Anbeilung getrockneter und feucht aufbewahrter Hautläppchen. - D. Zeitschr, f. Chir. Bd. 48. 1898. 
lich, zur Zeit noch grosse Differenzen; sogar bei scheinbar gleichbleibendem Verfahren sind die Experimente von verschiedenen Erfolgen begleitet. Vielleicht werden weitere Nachprüfungen bald mehr Klarheit in dieses Gebiet bringen. Einstweilen darf es uns nicht Wunder nehmen, dass grosse Verschiedenheiten sich ergeben, da wir erst am Anfange eines Forschungsgebietes stehen und nur einige der schädigenden Einflüsse, so die Bakterien, genauer kennen, während wir über die Bedingungen, welche der Efhaltung des Lebens förderlich sind, nichts wissen.

Dass die Kälte einen gewissen wohlthätigen Einfluss auf die Conservirung der Gewebstheile hat, scheinen die vorliegenden Versuche zu ergeben. Hiermit übereinstimmend sind auch die Beobachtungen von Ollier, auf dessen Periost-Transplantationen wir unten näher eingehen werden. Hier seien nur seine Angaben ${ }^{1}$ ) erwähnt, dass 18 bis 24 Stunden alte Iappen, bei $2-5^{\circ}$ unter Null aufbewahrt, voluminösere Knochenkerne ergeben hätten, als Lappen, welche in Temperaturen von $+15^{\circ}$ bis $+20^{\circ}$ aufgehoben waren. Unserer Kenntniss entziehen sich aber Factoren, wie die Lebensenergie der Zellen, wie sie z. B. den Epithelien gerade bei ihrer Abtragung innewohnte, und die Verhältnisse des Bodens, auf welchen nach der Aufbewahrung: die Ueberpflanzung erfolgte.

Wenn von den Flimmerpithelien der exstirpirten Nasenpolypen, die scheinbar unter gleichen Bedingungen aufbewahrt waren, die ungeheure Mehrzahl nach einigen Tagen abgestorben war, so erscheint uns die Bakterien-Wucherung als ausreichender Erklärungsgrund dafür. Wenn aber ungeachtet der Bakterien einige Zellen noch am 18. Tage Contractilität und glänzendes Protoplasma zeigen, so wissen wir absolut Nichts über die Ursache dieser Widerstandsfähigkeit.

Der Begriff "Lebenskraft" oder Lobstein's "Nervenkraft" ist nach harten Kämpfen aus der modernen Medicin hinausgedrängt worden; allein seit die Bakteriologie uns über sehr verschiedene Grade der Virulenz pathogener Mikroben belehrt hat, und seitdem es allgemeiner anerkannt worden ist, dass der menschliche und thierische Organismus „Schutzvorrichtungen“ be-

1) Ollier: Nouvelle note sur les greffes périostiques. Compt. rend. de l'Acad. des Seiences à Paris. T. 52. 1861. 
sitzt, mittelst derer er in gewissem Umfange pathogene Mikroben vernichten kann, seitdem tritt wieder das Bedürfnis hervor, der gesteigerten oder herabgesetaten "vitalen Energie" einen wichtigen Einfluss zuzuschreiben. Die Forschungen über die Serumtherapie haben un gezeigt, eine wie grosse Bedeutung der biologischen Lebensenergie zukommt; sie haben bewiesen, dass wir mit den bisher bekannten Factoren die thatsächlich vorhandenen Wirkungen nicht erklären können. Es muss daher jeder Weg versucht werden, der die Aussicht auf Erweiterung unsrer Kenntnisse von der Energie des Zelllebens bietet.

B. Vita propria des Periosts.

Ich habe es im Jahre 1896 unternommen, die im Vorstehenden erwähnten biologischen Fragen für das Periost zu untersuchen, da die Neigung des Periosts, bei gesteigerter Ernährung Knorpel and Knochengewebe zu bilden, einen sicheren Maassstab für die Beurtheilung giebt und Zweifel an der activen Betheiligung dieses Gewebes nicht aufkommen lässt.

Lange war zwar die knochenbildende Eigenschaft des Periostes strittig gewesen, und erst eine geraume Zeit verstrich, ehe dieselbe in richtiger Weise gewürdigt wurde.

Schon 1836 hatte Bernhard Heine ${ }^{1}$ ) seine Studien über die Regeneration der Knochen aus dem Periost veröffentlicht. Die reiche Sammlung seiner Beweisstücke soll noch eine sehenswürdige Abtheilung der Sammlung des Würzburger anatomischen Instituts bilden. Einige Hauptversuche stützten sich auf die Neuanlage von Rippen an Stellen, wo die ursprüngliche Rippe unter Erhaltung und Zurücklassung ihres Periosts total entfernt worden war.

Bemerkenswerth ist die Thatsache, dass Heine, als er seine Präparate der Académie des Sciences zu Paris (im Sommer 1834) vorlegte, von Seiten Flourens' nur eine bedingte Beistimmung fand, und es erst dem französischen Chirurgen Ollier gelang, dem Periost diejenige Anerkennung als Knochenregenerator zu verschaffen, welche ihm thatsächlich zukommt.

1) B. Heine: Ueber die Wiedererzengung neuer Knochenmasse und die Bildung nener Knochen. Gräfe und Walther's Journal der Chir. und Augenbeilk. Bd. 24. 1836. 
In einer grossen Anzahl von Experimenten, welche er in einer Reihe von Arbeiten veröffentlicht hat ${ }^{\mathbf{1}}$, legte 0llier seine Erfahrungen nieder.

Am reinsten brachte er die knochenbildende Thätigkeit des Periosts dadurch zur Anschauung, dass er grössere Periostlappen einem Thiere entnahm, und diese einem anderen Thier zwischen einige Muskelbäuche brachte. Er erzielte dabei z. Th. grössere, z. Th. kleinere Knochenstücke: Am 4.-5. Tage sah er die Wucherung der Knorpelzellen, am 7. und 8. Tage die Ablagerung von Kalksalzen. Als matrix des Knochengewebes erkannte er eine innere Zellschicht des Periosts, das Blastème souspériostale, bezw. die Couche ostéogène, von anderen Autoren Proliferationsschicht $\left.(\text { Virchow })^{2}\right)$, Cambiumschicht (Billroth) ${ }^{3}$ ), periostales Mark (Ranvier) ${ }^{4}$ ), osteoplastische Schicht (Strelz off) ${ }^{5}$ ) genannt.

1) L. Ollier: Recherches experimentales sur la production artificielle des os, au moyen de la transplantation da périoste et sur la régéneration des os après les résections et les ablations complètes. Journ. de la Physiologie. Tom. II. Paris 1859.

De la production artificielle des os au moyen de la transplantation du périoste et des greffes osseuses-Mémoires de la Société de Biologie. Paris 1859.

De la transplantation des eléments anatomiques du blastème souspériostal; formation des petits grains osseux dans la region où ont été semés ces éléments. Comptes rendus des séances de la Société de Biologie à Paris 1860.

Nouvelle note sur les greffes périostiques. Compt. rend. de l'Acad. des Sciences à Paris. T. 52. 1861.

Traité expérimental et elinique de la régéneration des os et de la production artificielle du tissu osseux. Paris 1867.

Ollier: Recherches expérimentales sur le mode d'accroissement des os. Arch. de phys. normale et pathol. No. 1. 1873.

Ollier: La regéneraton des os et les résections souspériostales. Paris. 1894.

2) Virchow: Ueber Bildung und Neubildung von Knochengewebe. Monatsschr. der Berl. Acad. Bd. VI.

3) Billroth: Anat. Beobachtungen über das normale Knochenwachstum, äber Periostitis und Caries. Arch. f. klin. Chir. Bd. VI, 1865.

4) Ranvier: De la préparation da tissu osscux avec le bleu d'aniline Arch. de phys. norm. et patholog.

5) Strelzoff: Ueber die Histogenese der Knochen. Unters. a. dem pathol. Inst. zu Zürich. 1. Heft. 
Die Wichtigkeit dieser Schicht bewies er noch durch besondere Versuche. Schädigte er sie durch mechanische Insulte oder durch Aetzen mit Chemikalien, so sah er keine Knochenbildung auftreten; wohl aber konnte er kleinste Knochenkerne erzielen, wenn er diese Schicht abkratzte und anderen Thieren zwischen die Muskeln transplantirte.

Was die histologischen Befunde betrifft, so sei nur erwähnt, dass er sowohl Knorpel, wie auch richtiges Knochengewebe mit Markräumen bei Untersuchungen der Endprodukte des transplantirten Periosts fand.

In späterer Zeit sind verschiedene ähnliche Transplantationen vorgenommen worden.

Buchholz ${ }^{1}$ ) hat eine ganze Reihe entsprechender positiver Resultate erzielt. Er bestritt zwar die Existenz des subperiostealen Blastems, glaubte vielmehr, der ganze Periostlappen diene zur Erzeugung des Proliferations-Produktes. Uns interessirt nur, dass er:

am 7. Tage die Bildung von Knorpel, in welchem die Ossification begann, und

am 14. Tage wirklich neugebildeten Knochen beobachtete. Auch bei direkter Einbringung, des Periosts in die Blutbahnen, welche Experimente zwar aus anderen Gründen ausgeführt warden, sahen Cohnheim und Maass'), "dass das Periost im Innern von Blutgefässen Knochen zu produciren vermag“. Auch noch bei anderen Untersuchungen lieferte Maass ${ }^{3}$ ) den Nachweis, dass aus ihrer Verbindung gelöste und in irgend ein anderes Gewebe verpflanzte Perioststücke wachsen und neuen Knochen bilden können.

Zur Lösung verschiedener Fragen bediente sich Bonome $\mathrm{e}^{4}$ ) auch der Transplantation von Periostlappen. Er erzielte nicht

1) R. Buchholz: Einige Versuche über künstliche Knochenbildung. Dieses Arch. Bd. 26. 1863.

2) Cohnheim und Maass: Zur Theorie der Gesebwulstmetastasen. Dieses Arch. Bd. 70. 1877.

3) Maass: Ueber das Wachsthum und die Regeneration der Röhrenknochen mit bes. Berücksichtigung der Callusbildung. Langenb. Arch. f. klin. Chir. XX. Heft 4.

4) M. Bonome: Zur Histogenese der Knochenregeneration. Dieses Arch. Bd. 100. 1885. 
nur bei Verbringung des Periostes zwischen Muskeln, wie es meist geschehen war, sondern auch bei Einführung in die vordere Augenkammer und die Iris Proliferations-Produkte.

Die Erscheinung, dass als Proliferations-Produkt man zuweilen eine beträchtliche Hyperplasie der osteogenetischen Schicht mit directen Uebergängen der Zellen derselben in wirkliche Osteoblasten und in anderen Fällen Knorpelsubstanz, die Vorläuferin des Knochengewebes, erhält, glaubt er durch den Grad der Intensität des Reizes, der auf das in Regeneration übergehende Gewebe ausgeübt wird, erklären zu könnén. Der Ort der grössten Reizung sollte Knorpelbildung erzengen, wie wir es auch bei der Callusbildung finden.

Wie man sich nun auch diese Erscheinung erklären mag, so ist das vergleichende Heranziehen der Calluswucherung wohl berechtigt.

Die Bilder, welche bei der Calluswucherung sich finden, stimmen zum grossen Theil völlig mit denen der ProliferationsProdukte bei der Periost-Transplantation überein, nur dass wir bei letzteren reinere Resultate erzielen, da hier die Betheiligung der anderen, bei der Fractur gereizten Gewebe fortfällt. Daher dürften die Transplantations-Produkte ein noch günstigeres Object zum Studium der Entwickelung von Knorpel aus zelligem Keimgewebe sein, als der in Entwickelung begriffene Callus, auf welchen seinerzeit Kassowitz ${ }^{1}$ ) hingewiesen hat.

Ich will nun nicht näher auf die verschiedenen Anschauungen über die Histogenese der Knorpelgrundsubstanz eingehen, wie sie von Remak ${ }^{2}$ ), Heidenhain ${ }^{3}$ ), Strasser ${ }^{4}$ ) u. A. vertreten sind. Vielmehr beschränke ich mich darauf, wegen der nahen Parallele noch kurz einige Angaben über die ersten Stadien der Periostwucherung za machen, welche $\mathrm{Krafft}^{5}$ ) bei seinen

1) Kassowitz: Die normale Ossification. Wien 1881.

2) Remak: Ueber die Entstehung des Bindegewebes und des Knorpels.

J. Müller's Arch. $185 \%$.

Remak: Untersuchungen über die Entwickelung der Wirbeltbiere. 1855.

3) R. Heidenhain: Zur Kenntniss der Struktur des byalinen Knorpels. Studien aus dem physiol. Inst. zu Breslau.

4) H. Strasser: Zur Entwickelung der Extremitätenknorpel bei Salamandern und Tritonen. Leipzig 1879.

5) E. Krafft: Zur Histogenese des periostalen Callus. Ziegler's Beitr. Bd. I. 1886 . 
genauen histologischen Untersuchungen des periostealen Callus gefunden hat.

Bis zum. 2. Tage berrscht stetig zunehmende, entzündliche Exsudation vor.

Granulationsgewebe als Vorgewebe des Periostcallus feblt.

In den Osteoblasten finden sich nach 48 Stunden zahlreiche Karyokinesen.

Am 3. Tage besteht eine starke Wucherung sämmtlicher Periostschichten, besonders der schon nach 48 Stunden verdickten Keimschicht.

Die Zwischensubstanz ist verbreitert und färbt sich dunkler (mit Hämatoxylin und Carmin-), im Gegensatz zur Grundsubstanz des hyalinen Knorpels.

Die Grundsubstanz des Keimgewebes ist sehr durchsichtig, von fibrillärem Bau; ihre Zunahme erfolgt wohl durch Umwandlang von Zellprotoplasma, wie es auch Kassowitz annimmt. Die Grenze zwischen Faser- und Keimschicht ist durch Zellwucherung in ersterer verwischt.

Kerntheilungs-Figuren sind in beiden vorhanden. Von der Oberfläche des gebrochenen Knochens aus differencirt sich, in zuerst nur schmaler Schicht, unter Umwandlung der Zwischensubstanz des Keimgewebes, ein osteoides Gewebe.

Am 4. Tag verbreitert sich durch $W$ ucherung der osteoplastischen und streifigen Schicht die osteoide Zone, welche dabei in dendritischer Verbreitung in das Keimgewebe hineinwuchert oder vielmehr sich aus demselben heraus differencirt.

Constant finden sich neben der osteoiden Gewebszone kleine Inseln von Hyalinknorpel.

Endlich bildet sich da und dort ein zwischen Knorpel und osteoider Substanz morphologisch die Mitte haltendes Gewebe, welches von Kassowitz treffend als "chondroide Madification des osteoiden Gewebes" bezeichnet worden ist. Die Zellen stimmen mit der Form der Knorpelzellen überein und liegen in einer runden Zellhöhle, während die Zwischensubstanz mit der des osteoiden Gewebes morphologiseh und chemisch vollkommen übereinstimmt, aber bindegewebigen, keimgebenden Charakter trägt und auch dieselbe Affinität zum Farbstoff besitzt. 
Ein Punkt, welcher bei den Untersuchungen wenig oder gar nicht beachtet wurde, war das Verhalten der elastischen Fasern.

Einmal giebt Buchholz (a. a. 0.) an, dass am 6. und 7. Tage nach der Transplantation die Zellen des gesammten Periosts grösser werden, auseinanderrücken durch Dazwischenschieben einer homogenen Grundsubstanz und durch gruppenoder reihenweise Lagerung die elastischen Fasern auseinanderdrängen. Auch in der Abbildung eines 6 Tage alten Periost-Produkts zeichnet er einen Knorpel, durchzogen von elastischen Fasern.

In ähnlicher Weise beschreibt Bajard ${ }^{1}{ }^{1}$ ), wie bei der Callusbildung in der Nähe der Bruchenden am 4. Tage Inseln von hyalinem Knorpel auftreten, "dessen Grundsubstanz von den elastischen Fasern analogen Gebilden" durchsetzt werde.

Dass das Verhalten der elastischen Fasern des Ferneren wenig oder gar keine Beachtung fand, darf uns nicht Wunder nehmen, da volle Klarheit über ihr Vorkommen im Knochen und Periost erst in jüngster Zeit geschaffen ist. Onter Bonnet's Leitnng hat $\mathrm{Schulz}^{2}$ erst die Grundlagen für eine genauere Kenntniss dieser Verhältnisse gelegt.

Nach ihnen zerfällt das Periost in drei Schichten:

1. die Adventitia, bestehend aus fibrösem, ziemlich derbem, kernarmem Bindegewebe mit reichlichen Gefässen und Nerven, welche weiter central in die Beinhant eindringen, während peripherisch ein allmählicher Uebergang in das interstitielle Bindegewebe der benachbarten Musculatur stattfindet. Elastische Elemente sind spärlich vorhanden.

2. die Fibro-Elastica, aus ziemlich gleichmässig dicken fibrösen Bündeln bestehend. Sie ist auffallend gefässarm, aber scharf gegen die Adventitia und Osteoblastenschicht durch ihren enormen Reichthum an elastischen Fasern abgegrenzt, welche parallel zur Knochenaxe verlaufen.

3. die osteoblastische Schicht, welche sich aus einer lockeren bindegewebigen und der zellreichen Osteoblasten-Schicht

1) D. Bajardi: Teber die Bildung und Rückbildung des Callus bei den Brüchen der Röhrenknochen. Molesch ott's Untersuchungen. Bd. XII. 3.-4. Heft.

2) K. Schulz: Das elastische Gewebe des Periostes der Knochen. Inaug.-Diss. Giessen 1895. (Wiesbaden. Bergmann's Verlag.) 
in engerem Sinne zusammensetzt. Letztere besitzt beim Neugeborenen absolut keine elastischen Elemente. Beim Erwachsenen findet jedoch eine Umwandlung der Osteoblasten-Schicht in fibröses Gewebe statt, indem die Fibro-Elastica sich auf ihre Kosten bis dicht an den Knochen ausbreitet, wodurch die elastischen Fasern diesem natürlich näher gerückt werden.

In ähnlicher Weise verhalten sich die elastischen Fasern im Knochen. Beim Neugeborenen finden sich absolut keine, während beim Erwachsenen solche (im Röhrenknochen) oft ganz regellos verlaufen, bald schief die Lamellensysteme durchbohrend, bald stellenweise zwischen ihnen, bald Netze bildend.

Bedingt erscheint dies verschiedene Auftreten der elastischen Fasern in erster Linie durch die von Nachbarorganen (Muskeln, Bändern, Fascien) her auf die Beinhaut wirkenden Druck- und Zugkräfte, wie es Bounet in ähnlicher Weise auch an anderen Organen, so den Gefässen, nachgewiesen hat.

Wir sehen aber, dass die physiologischen und histologischen Kenntnisse über die Function und das Wachsthum des Periosts ausserordentlich im Laufe der Jahre vertieft worden, und dass Klarheit in die einschlägigen Verhältnisse gebracht wurden ist. Völlig zurück blieb aber die biologische Seite in dieser Frage.

Ich muss hier wieder auf 0llier zurückgehen.

Mehr zufällig batte er bei seinen Transplantationen festgestellt, dass Periost, welches einem Kaninchen 24 Stunden nach dessen Tode entnommen und auf ein anderes Kaninchen transplantirt wurde, noch lebensfähig geblieben war und Knochen producirt hatte. Er äussert sich darüber: "Ces nouvelles expériences démontrent ainsi que des éléments anatomiques peuvent conserver très-longtemps leur vitalité et leur propriété de croissance malgré la cessation des fonctions essentielles à la vie de l' organisme entier". So wunderbar ihm diese Beobachtung auch erschien, so scheint bisher niemand dieser Frage näher getreten zu sein; im Gegentheil, sie ist im Laufe der Zeit anscheinend völlig dem Vergessen anheimgefallen. Ich unternahm daher derartige Periost-Transplantationen speciell mit der Berücksichtigung, wie lange die Vita propria des Periosts sich noch nach

1) L. Ollier: Nouvelle note sur les greffes périostiques. Compt. rend. de l'Acad. des Sciences à Paris. T. 52. 1861. 
dem Tode des Thieres erhält. Die Resultate sollen im folgenden Abschnitt geschildert werden.

\section{Eigene Transplantations-Versuche.}

Es kam mir bei meinen Transplantationen nicht auf den Modus der Periost-Proliferationen an, den wir ja im vorigen Capitel kennen gelernt haben, sondern mein Zielpunkt war, zu ergründen: Können die Zellen des Periosts überhaupt, und zutreffendenfalls, wie lange, ihre Vita propria im weitesten Sinne, also auch die Proliferations-Fähigkeit, nach ihrer Loslösung vom Gesammt-Organismus bewahren?

Es war selbstverständlich, dass ich die günstigsten Bedingungen für meine Versuchsobjekte zu schaffen versuchte.

Ich zog daher die Consequenzen aus den reichen Erfahrungen, welche besonders Ollier durch viele Experimente gewonnen hatte, wobei ich unterstützt wurde durch die neueren a- und antiseptischen Fortschritte, welche Ollier wenigstens in seinen unsere Frage betreffenden Untersuchungen nicht hatte berücksichtigen können.

Ich versuchte mir zunächst ein möglichst junges und dabei kräftiges Thiermaterial zu verschaffen.

Es ist eine festgestellte Thatsache, dass die osteoblastische Schicht des Periosts beim Erwachsenen ganz bedeutend ärmer an osteoblastischen Keimzellen ist, als die bei jugendlichen Individuen.

Die Fibro-Elastica ist es, welche sich nach Schulz (a.a. 0.) bei Röhrenknochen Erwachsener, wie schon erwähnt, bis dicht an den Knochen auf Kosten der osteoblastischen Schicht, von welcher nur Reste übrig bleiben, ausbreitet.

Die Thiere, welchen das Periost entnommen werden sollte, wurden durch Schlag ins Genick getötet, ihre Eingeweide sofort entfernt und oun in grossen Glasschalen auf Eis oder in kalten Räumen, je nach der Jahreszeit, aufbewahrt, d. h. in Temperaturen von ungefähr $\pm 0^{\circ}$ bis $+4^{\circ} \mathrm{C}$.

Dass die niederen Temperaturen für die Erhaltung der Vitalität der Zellen nicht nur nicht schädigend, sondern vielmehr anscheinend sehr vortheilhaft sind, hatte schon Ollier, wie 
oben erwähnt, berichtet. Dieselben haben sich ja auch für die Vita propria der Thiersch'schen Lappen als günstig erwiesen. Durch die von mir angewandte Aufbewahrung war gleichzeitig das periosteale Gewebe bis zu seiner Transplantation möglichst vor äusseren Insulten geschützt.

Zu den Transplantationen benutzte ich Periost von der Tibia und vom Radius.

Diese Knochen haben sich zur Entnahme besonders bewährt, so bei Ollier und Buchholz. Ob sie vielleicht einen besonderen Reichthum an osteoblastischer Keimschicht besitzen, ist noch nicht näher studirt; auf jeden Fall bieton sie technisch zur Ablösung die günstigsten Bedingungen.

Bei jugendlichen Individuen kann man mit ausserordentlicher Leichtigkeit nach einer sorgfältigen und vorsichtigen Abpräparirung der anliegenden Muskeln das Periost in ansehnlichen Lappen (je nach der Grösse des Thieres) abziehen. Man umschneidet den Knochen in der Nähe der beiden Epiphysen, spaltet das Periost senkrecht an einer Stelle, so an der Crista tibiae, und hat nun kaum nöthig, mit scharfen Instrumenten zu schaben oder zu kratzen, höchstens dass man einmal mit dem stumpfen Scalpelstiel nachhilft.

Ich erwähne dies ausdrücklich, da mir das Bedenken erhoben wurde, ob nicht doch Theile des Knochens mit dem Periost entfernt seien, welche gewisse Befunde vortäuschten.

Wenn man einmal derartige Periost-Abtragungen gemacht hat, müsste man sehr rücksichtslos gegen das Gewebe vorgehen, um solches zu erreichen. Um aber ganz sicher zu gehen, habe ich eine Reihe von Control-Präparaten hergestellt, indem ich Serienschnitte durch ebenso gewonnene Periostlappen von der anderen Extremität der betreffenden Thiere herstellte, und ich kann versichern, dass ich niemals auch nur die Andeutung eines mitgerissenen Knochensplitters oder irgend solche Bilder gefunden habe, wie sie im Folgenden beschrieben werden sollen; vielmehr waren nur die Schichten des Periosts vertreten.

Die abpräparirten Periostlappen wurden sodann in sterile Kochsalzlösung für einige Zeit gelegt, um sie unter möglichst schonender Behandlung ausbreiten und ausgebreitet auf einen Spatel bringen zu können. Sie verblieben nur einige Minuten 
darin, so lange, bis die weitere Operationsbasis, welche vorher schon vorbereitet war, völlig zur Aufnahme fertig war.

Implantirt wurde auf Thiere der gleichen Gattung. Die folgenden positiven Resultate stammen alle von Kaninchen, und, durch einige besonders günstige Resultate veranlasst, benutzte ich schliesslich zu den Transplantationen nach Möglichkeit Thiere von einem Wurf. Es mag ja Zufall sein, dass ich bei diesen Versuchen gerade mebr Erfolg hatte; aber nach mannichfachen Misserfolgen unterzieht man die einzelnen Factoren einer um so schärferen Kritik, und über den Chemismus und das Verhalten der einzelnen Zelle sind wir heate doch noch so im Unklaren, dass auch der fragliche Punkt der Verwandtschaft vielleicht eine günstige Rolle spielen könnte.

Als Ort der Implantation wählte ich, entsprechend den meisten früheren Versuchen, die Musculatur des Oberarms und des Oberschenkels. Besonders letzterer ist möglichst den Insulten seitens des Thieres durch Knabbern und Aehnliches entzogen; dann kann man an ihm bequem den Periostlappen zwischen die lateralen Muskelbäuche einbringen und gut ausgebreitet mit einigen Nähten fixiren, ohne dass eine wesentliche Blutung entsteht. Das Festnähen ist nöthig, da sonst das so wie so zum Einrollen neigende Periost sich zusammenballt und die Proliferation erfahrungsgemäss Störungen erleidet. Nach Muskel-, bezw. Fascienund Hautnaht wurde die Wunde mit Jodoform-Collodium bedeckt.

Die Zeit, nach welcher unter danernder Controle eine Wiederöffnung des Implantationsfeldes stattfand, richtete sich je nach ${ }^{2}$ den Verhältnissen. Es kam mir zunächst ja nicht auf histologische Einzelfragen an, sondern nur auf die principielle Beobachtung von Proliferations-Erscheinungen.

So revidirte ich je nach dem Aussehen der Wunde, oder wenn eine Proliferation eingetreten zu sein schien, eine Knochenbildung schon fühlbar war, oder scheinbar ein Schwund des transplantirten Gewebes stattgefunden hatte.

Bei der Revision wurde nach Tödtung des Thieres, damit das Gesichtsfeld vor Trübung durch Blutung oder Aehnlichem bewahrt werde, meist der obere Muskel fortgenommen, um das Perioststück makroskopisch besichtigen za können. Waren Verwachsungen mit diesen eingetreten, so waren dieselben meist 
sehr leicht zu lösen, da sie oft ganz dünne Stränge bildeten, welche wohl durch die Bewegung des Muskels entstanden waren.

Mit der Unterlage, auf welcher sie fixirt und inniger verwachsen waren, wurden dann die Periostlappen, oder richtiger gesagt die Endprodukte im Zusammenhang herausgeschnitten und nun in Müller'scher Flüssigkeit, Flem ming'schem Säuregemisch oder Alkohol, je nachdem es zweckmässig erschien, fixirt. Die dann vorgenommenen Färbungen in HämatoxylinEosin oder Carmin, Anilinsaffranin oder Carbolfuchsin, und zum Zwecke der Darstellung der elastischen Fasern in Orcein richteten sich je nach dem Modus der Fixation. Die beschriebenen Resultate sind zuweilen Combinationen aus den verschiedenen Methoden.

Die folgende Darstellungsreihe richtet sich im Wesentlichen, entsprechend dem $Z_{\text {wecke, }}$ zu dem die Experimente unternommen wurden, nach der Zeit, welche zwischen der Tödtung des Stammthieres und der Transplantation des Periosts auf den Wirth lag.

Was schliesslich das Thiermaterial betrifft, so wählte ich, ebenso wie Ollier, Kaninchen, besonders nachdem eine Reihe von Transplantationen bei Katzen und Meerschweinchen nicht von dem gewünschten Erfolge, z. T. wohl durch äussere Umstände veranlasst, begleitet waren.

Es ist mir nun gelungen, unter Anwendung der mitgetheilten Verfahren nicht nur die von Ollier erzielten Ergebnisse über die Vita propria des Periosts zu erreichen, sondern dieselben noch um ein Beträchtliches zu übertreffen. Ich lasse die Beschreibung folgen:

I. 29 horas post mortem, 7 dies post operationem. (positiv; Fig. 1.)

Am 28. Mai 1897 morgens 7 Uhr wird ein etwa 6 Wochen altes Kaninchen getödtet. Demselben wird 29 h. post mortem von einem Radius ein Stück Periost entnommen und einem etwa 3 Monate alten Kaninchen zwiscten die Muskelbäuche der Extensores antibrachii geschlungen.

Am 7. Tage post operationem fühlt man an der Operationsstelle einen dicken länglichen Wulst durch die Haut. Beim Freipräpariren findet sich das Periost als dünner, stricknadeldicker Strang spiralig gedrebt. Das obere Ende ist anscheinend in eine käsige Masse ungewandelt. Die untere Hälfte dagegen stellt eine derbe, knorpelartige Partie von milchig-weissem 
Aussehen dar. Das Objekt wird in toto in Flemming'scher Flüssigkeit fixirt. Färbung in Saffranin, Carbolfuchsin, Orcein.

Mikroskopisch finden sich nun in den etwa $15 \mathrm{~mm}$ langen und $3 \mathrm{~mm}$ breiten Schnitten, welche senkrecht zur Periostfläche angefertigt and in der Mitte sanduhrförmig eingezogen sind, bei schwacher Vergrösserung folgende Bilder:

Die eine Längsseite des Präparates ist eingenommen von vielen Streifen von Musculatur. Die Bündel sind an einzelnen Stellen durch Blutungen auseinandergedrängt. Mit dem Muskel in innigem Zusammenhang steht eine breitere Partie eines zellreichen Bindegewebes, z. T. vom Typus des GranulationsGewebes, welches vielfach die Interstitien zwischen den Muskelbündein einnimmt. Zahlreiche kleinere und grössere Gefässe finden sich in demselben. Hieran schliesst sich oberhalb und unterbalb der sanduhrförmigen Einschnürung je eine ovale Insel von Knorpelgewebe. Die obere hat einen grössten Breitendurchmesser von $0,8 \mathrm{~mm}$ und Längedurchmesser von 1,85 mm, die untere von $0,8 \mathrm{~mm}$ und $1,3 \mathrm{~mm}$. Deutlich setzen sich die Inseln ab von dem oben beschriebenen Gewebe, zunächst durch eine Zone von langen, spindeligen Zellen. Die mit Orcein gefärbten Präparate zeigen bier einen breiten Saum von langgezogenen, feinen, intensiv gefärbten elastischen Fasern. Dieser ist besonders gut an der oberen Insel zu seben. Dieses Band zieht sich auch durch die Einschnürung zwischen den beiden Knorpelpartien; hier sind aber die Fasern z. T. sehr stark geschlängelt, wie zusammengeschnurrt. Nur ein Theil zieht wieder zu der unteren Linie hin, wo aber der Saum lange nicht so ausgesprochen ist.

Der Umstand, dass der knorplige Wucherungstheil (bes. deutlich der obere) ringsum von ruhendem, derbem Periost umgeben ist, lässt wohl annehmen, dass wir es hier nicht mit einem reinen idealen Querschnitt durch das Periost und seine Proliferations-Produkte zu thun haben. In diesem Falle möchten wir dort, wo der Saftstrom hingetreten, die am meisten vorgeschrittene Proliferation erwarten und an der entgegengesetzten Seite müsste die Wucherung ausklingen. In unserem Falle ist die Peripherie aber relativ ruhend.

Hier bat sich jedenfalls das Perioststück aufgerollt. Das kommt häufig vor und ist auch von Ollier of beschrieben; selbst die Fixation durch Nühte kann es nicht immer verhindern. Bei diesem Aufrollen hat sich die Keimschicht nach innen gelegt, und gleichsam central, in einer Art von Cylinder aus Periost, hat die Knorpelwucherung eingesetzt. Ein Längsschnitt hindurch erklärt dann obige Configuration.

Ein Einrollen findet natürlich auch an den Enden statt, zudem kann der Periostlappen als solcher eine Knickung in eine andere Ebene durchgemacht haben, so dass Bilder, wie die getrennt von einander liegenden. Knorpelinseln, entstehen kännen.

Wir betrachten nun bei Oel-Immersion diese Zone:

An die mehr oder weniger regellos gelagerten Zellen des GranulationsGewebes schliessen sich als nächstliegende Theile des Periosts Zäge von 
langen, spindelförmigen Zellen. Ihr Kern ist gross, länglich, ziemlich schmal und besitzt ein, zuweilen auch zwei Kernkörperchen. Die Zellen liegen alle parallel, oft dicht zusammen, zuweilen in Reihen hintereinander. An einzelnen Stellen sind sie durcb eine feinstreifige, im Präparat gelblichbraun tingirte Zwischensubstanz geschieden, die sich nicht iromer scharf von den Zell-Leibern abgrenzen lässt.

Mehr nach innen (zum Knorpel zu) werden die Kerne grösser, speciell breiter und nehmen eine mehr rundliche Form an, die Abstände zwischen den Zellen werden grösser, die Zwischensubstanz wird heller, ihre faserige Struktur ist deutlich zu erkennen. Zahlreiche Mitosen finden sich in diesem Gebiet (Fig. $1 \mathrm{~m}$ ) in den verschiedensten Stadien der Karyokinese. In der Grundsubstanz sieht man hie und da kleinste helle Gewobskerne auftauchen, in denen zuweilen noch nichts ron Kernkörpern zu erkennen ist. Die rege Thätigkeit der osteoblastischen Keimschicht (0) tritt hier zu. Tage.

Fernerhin nimmt die $Z$ wischensubstanz rapide $\mathrm{zu}$, indem sie ein homogenes Aussehen und bei Saffraninfärbung eine leicht bläulich-rothe Färbung zeigt. Dazwischen liegen die Zellen, deren Grösse und Form nun böchst variabel geworden ist. Der Kern mit gut gefärbtem Chromatingewebe ist gross; das Zellprotoplasma hebt sich in gelber Farbe deutlich ron der Zwischensubstanz ab. Diese bildet bald eine Kapsel um dieselben. Der Typus der Knorpelzelle ist hergestellt (Fig. 1 k). Die Knorpeizellen zeigen nun die verschiedensten Anordnungen. Hier liegt eine mächtige Knorpelzelle, umgeben von einem grossen Hof von Zwischensubstanz; dort liegen zwei Tochterzellen (A) nahe zusammen, an anderen Stellen sind sie in Reiben hintereinander geordnet.

In einzelnen Präparaten finden sich Gefässe, welche man manchmal von der Peripherie aus verfolgen kann, manchmal ohne erkennbaren Zusammenhang mitten in der Knorpelinsel antrifft. Die Knorpelgrundsubstanz in ihrer Umgebung ist geschwunden, die Knorpelzellen liegen dicht zusammen und zeigen stellenweise eine beginnende Anordnung zu grösseren Zügen, wie wir es bei der Bildung des osteoiden Gewebes sehen. Hier liegt also die erste Anlage zu chondroiden Balken vor.

Die zweite im Präparat vorbandene Knorpelinsel verbält sich in ihrer Entwickelung ebenso, wie dies oben beschrieben. Die Intensität der Wucherung der einzelnen Knorpelzellen ist jedoch nicht so bedeutend, wie dort. Die Zellen zeichnen sich durch eine geringere Grösse aus, auch die Knorpelgrundsubstanz ist nicht so reichlich vorhanden. Was hier aber zu Tage tritt, das sind Mitosen in den Knorpelzellen noch in der Mitte der Knorpelinsel.

Beide Knorpelinseln sind, wie erwähnt, durch eine bindegewebige Brücke verbunden. An Stelle der Knorpelzellen jederseits treten allmäblich wieder mehr spindlige Formen, bis wir nur grosse Bindegewebszellen haben. An einem Theil derselben ist die Kernstruktur zerstört und eine Verklumpung des Chromatins eingetreten, stellenweise ist überhaupt keine Kernfärbung 
mehr vorhanden, - Zejehen, dass hier eine Nekrose des Periosts stattgefunden hat.

Betrachten wir noch etwas genauer den Verlauf der elastischen Fasern:

An der äusseren Seite der oberen Knorpelinsel bilden sie, wie schon geschildert, einen ziemlich ausgesprochenen Saum, welcher die Fibro-Elastica des transplantirten Periosts darstellt. Derselbe ist zwar nicht so mächtig, wie wir ihn noch an späteren Präparaten sehen werden. Die elastischen Fasern, die besonders scharf bei Orceinfärbung, aber auch deutlich bei Saffranin- und Fuchsinfärbung zu erkennen sind, verlaufen in langen, leicht gewellten Linien (e). Zwischen ihnen liegen die ziemlich reichlichen Spindelzellen der Fibro-Elastica. Dem Knorpel zu werden die Fasern nun gleichsam auseinandergedrängt durch die Proliferation der Zellen; sie ziehen mehr vereinzelt zwischen den Zellen der osteoblastischen Keimschicht hin, aber selbst bis in den in $\mathrm{n}$ ersten $\mathrm{Kern}$ der Knorpelinsel sind sie zu verfolgen. Reichlicber sind sie noch da zu finden, wo Gefässe in den Knorpel gewuchert sind.

In der bindegewebigen Brücke zwischen den zwei Knorpelinseln ist das Zusammenschnurren der Fasern schon erwähnt. Sie sind nicht so distinct gefärbt, sondern zeigen eine mehr massige Färbung, - Zeichen von Degeneration, wie wir sie auch an dem Bindegewebe daselbst gesehen haben. Nur einige scharfe, lange Fasern sind erhalten, um zur unteren Knorpel-Insel zu ziehen und sich hier nicht so ausgesprochen an der äusseren Seite derselben zu halten, sondern z. T. fächerförmig in dem Knorpel zu verlaufen.

Zusammenfassugg: Das Periost, welches 29 Stunden nach Tödtung des Stammthieres diesem entnommen und transplantirt wurde, zeigt in seinem oberen und unteren Abschnitt nach 7 tägigem Verweilen im Organismus des Wirthes reichliche Wucherung von hyalinem Knorpel. Der mittlere Abschnitt des transplantirten Periostlappens ist z. Th. zu Grunde gegangen.

Der Modus der Knorpelentwicklung (ähnlich, wie bei Krafft a. a. 0 . beschrieben) besteht, in der Fibro-Elastica schon anfangend, speciell aber in der Keimschicht in einer Vergrösserung der Zellen und dem Hervortreten zahlreicher Gewebskeime, die vielfach spiralig gedreht, vielleicht mit einander zusammenhängen; nach weiterem Wachsen zeigen sie Uebergang in mitotische Theilung und Metaplasie in Knorpelgewebe. Die elastischen Fasern der Fibro-Elastisa sind z. T. sehr gut in ihrer Structur erhalten, z. T. in die Wucherung mit einbegriffen und finden sich durch den ganzen neugebildeten hyalinen Knorpel wenn auch spärlich verstreut. 
II) 29 h. p. m. 7 T. p. op. positiv.

Einem am 28. Mai 1897 Morgens $7 \mathrm{Ubr}$ getödteten, etwa 6 Wocben alten Kaninchen ist am 29. Mai $189712 \frac{1}{2}$ Uhr mittags, also 29 Stunden post mortem, ein Periostlappen vom rechten Radius entnommen und einem ebenso alten Kaninchen von demselben Wurf um die Nusculatur des rechten Oberarms, geschlungen.

Am 5. Juni 1897, also 7 Tage post transplantationem, findet sich das Periost etwas zusammengerollt, sonst gut ausgebreitet und gut aussehend vor.

Fixation in Flemming'scher Lösung.

Mikroskopisch findet sich in dem etwa $12 \mathrm{~mm}$ langen und etwa $2 \mathrm{~mm}$ breiten Schnitt eine etwa $2 \mathrm{~mm}$ Iange und 0,75 $\mathrm{mm}$ breite Insel typischen osteoiden Gowebes.

In ähnlicher Weise, wie im vorhergehenden Fall, vergrössern sich die Zellen der Fibro-Elastica und der Keimschicht des Periosts. Es finden sich in ihnen versehiedene Kerntheilungs-Figuren; sie werden polygonal und weisen dann eine $\mathrm{Z}$ wischensubstanz auf. $\mathrm{Hi}$ er scbliesst sich eben nicht der Knorpeltypus an, sondern die Zellen werden bald zackig und legen sich reibenförmig hintereinander, um schliesslich mit reichlicher Zwischensubstanz Knochenbälkchen zu bilden, welche eine grosse Zahl länglicher und runder Markräume umschliessen. Dort, wo diese Markräume sich nach der Keimschicht hin öffnen, sieht man, dass die Osteoblasten sich in dieselben binein fortsetzen, bald in dünneren Zügen, bald grössere Complexe bildend. Sie halten sich vorwiegend am Rande der Markräume, während der übrige Markraum von ächtem Markgewebe ausgefüllt ist. Vereinzelt finden sich dort auch Riesenzellen.

Die übrigen Theile des Periosts tragen deutliche Zeichen des Absterbens in sicb. Kleinste, durch die Osmiumsäure schwarz gefärbte Fettkörnchen erfüllen eine grosse $Z$ ahl von Zellen, bis schliesslich kernarme, stark gequollene bindegewebige Partien nur noch von ihnen zurückbleiben.

Aber auch in diesem Degenerationsgebiete ist hie und da eine Mitose zu sehen. Der Fettmetamorphose ist eine starke Vergrösserung der Kerne voraufgegangen, sie liegen in dichter Gruppirung den zerklüfteten schmalen Bindegewebsbündeln an, wie in Fig. 1 fe.

Die elastischen Fasern sind fast in der ganzen Ausdehnung des Periosts gut erbalten. An dem Proliferations-Gebiet sind sie wieder etwas durch Zellenwucherung auseinanderdrängt. Ein Strang zweigt sich sogar völlig $a b$ und zieht mit der Osteoblastenschicht ein Geringes in die Marksubstanz des osteoiden Gewebes hinein. In diesem selbst sind keine Fasern nachzuweisen.

Zusammenfassung: Das 29 Stunden nach der Tödtung dem Thiere entnomwene und einem anderen - von demselben Wurf stammenden - Kaninchen implantirte Periost 
zeigt am 7. Tage eine schöne Proliferation in Gestalt einer $1,2 \mathrm{~mm}$ langen und $0,75 \mathrm{~mm}$ breiten Insel von osteoidem Gewebe. Die allmähiliche Bildung desselben aus den Osteoblasten des Keimgewebes ist deutlich zu verfolgen. In ibm und auch in den tieferen Schichten der Fibro-Elastica finden sich reichlichere Mitosen.

Die elastischen Fasern sind gut erhalten. Ein Bündel zieht in das Markgewebe der osteoiden Substanz. Ein grosser Theil des Periosts ist nach einem anfänglichen $W$ ucherungsstadium in Fettmatemorphose und Erweichung übergegangen.

III) 48 h. p. m. 3 d. p. op. positiv.

Einem etwa 3 Monate alten Kaninehen wird 48 Stunden nach seiner Tödtung ein Periostlappen von der rechten Tibia genommen und einem anderen Thiere von demselben Wurf zwischen die Musculatur des Oberschenkels transplantirt.

Am 3. Tage nach der Transplantation findet man das Periost gut ansgebildet, etwas geschwollen und sulzig verdickt.

Fixirung in Flemming'seher Lösung.

Mikroskopisch erscheinen die einzelnen Fasern der Fibro-Elastica etwas weiter von einander zu stehen, wie normal. In der sich anschliessenden Osteoblasten-Schicht finden sich noch verschiedene Mitosen in den verschiedensten Stadien der Kerntheilung. Von dem unterliegenden MuskelGewebe sind Granulationen zur Verbindung mit dem Periostlappen aufgeschossen, zwischen welchen feinste Gefässe zu den Muskelresten ziehen, welche bei der Transplantation dem abpräparirten Periostlappen noch anhafteten. Die Muskelbündel derselben sind aufgefasert und zeigen einen grossen Kernreichtbum.

Zusammenfassung: Ein 48 Stunden post mortem transplantirter Periostlappen zeigte am 3. Tage post transplantationen die ersten Zeichen einer beginnenden Proliferation in Gestalt von Mitosen in der osteoblastischen Schicht.

IV) 50 h. p. m. 6 d. p. op. positiv.

Dem am 28. Mai 1897 Morgens $7 \mathrm{Uhr}$ (cf No. I) getödteten, etwa 6 Wochen alten Kaninchen wird am 30. Mai morgens $\frac{1}{2} 10 \mathrm{Ubr}$, also 2 Tage und 2 Stunden $=50$ Stunden $n$ ach dem Tode, ron der rechten Tibia ein Periostlappen entnommen und einem etwa ljäbrigen Kaninchen zwischen die Musculatur des Rückens transplantirt.

Am 6. Tage nach der Transplantation findet sich das Periost nach Abziehen der oberen Muskelplatte gut ausgebreitet. Die obere Hälfte scheint ein wenig rerdickt und hat ein weisslich glasiges Aussehen; die untere Hälfte ist gelblich-opak und macht einen nekrotischen Eindruck. 
Fixation in toto in Flomming'scher Lösung.

Mikroskopisch sind nun in dem etwa $1 \frac{1}{2} \mathrm{~cm}$ langen, oben etwa $1 \mathrm{~mm}$, im unteren Theil etwa $0,3 \mathrm{~mm}$ breiten Querschnitt auch $z$ wei Theile $z u$ erkeunen; die untere Hälfte ist total nekrotisch, die obere zeigt ganz geringe Proliferations-Erscheinungen. Die eine Seite des Präparates ist gebildet von dem äusseren Blatte des Periosts, auf welchem einige Blutgerinnsel aufsitzen. Wir sehen im oberen Abschnitte, äbnlich wie bei Präparat no I, die spindelförmigen, langen Zellen der Fibro-Elastica, zwischen denen die elastischen Fasern in feiner Linie hinzieben. Eine scharfe Abgrenzung gegen die Keimschicht finden wir bier ebensowenig, wie in den auch in Flemming'scher Lösung gehärteten, vorher beschriebenen Präparaten. Aber bier sind nur einige Zelllagen breit die etwas umfangreicheren Uebergangsformen der Zell-Leiber und -Kerne zu sehen, dann setzt eine Zone ein, wo die elastischen Fasern stark geschlängelt, kürzer und plumper sind und breit auseinandergedrängt werden durch gequollene homogene Massen, die nur wenige normale Zellen, hier und da eine kleine Rundzelle mit gelapptem Kern oder Kernfragmente aufweisen. Hieran schliesst sicb ein ausserordentlich gefässreiches Granulationsgewebe.

Nur an einer Stelle der erst genannten Zelllagen findet sich eine bis $0,3 \mathrm{~mm}$ breite Zellgruppe, welche alle die schon früher (cf. no I) beschriebenen breiteren, bezw. mehrseitigen polymorphen Zellformen aufweist. In derselben finden wir mehrere, verschiedenartige mitotische Theilungen; ebensolche kommen auch dort noch vor, wo im allmăblichen Abschwellen der Wucherungszone nur noch einige Zellreihen nebeneinanderliegen. Die gute Kernfärbung derselben nimmt dann allmäblich zum unteren Ende ab, um schliesslich ganz aufzuhören. Nur hie und da findet man noch Andeutungen von Kernfärbung oder Chromatin-Bröckel; nur die klumpigen, oft kurzen Züge der elastischen Fasern treten durch die Färbung deutlich hervor.

Zusammenfassung: Periost, welches 50 Stunden nach Töd tung des Thieres entnommen wurde, zeigt am 6. Tage post transplantationen nur an einer kleinen Insel eine Proliferation, welche schon in den tieferen Schichten des Periostes beginnt und zur Bildung knorpelähnlicher Zellen geführt hat. Die übrigen Theile sind nekrotisirt. Die elastischen Fasern sind in den proliferirenden und gut erhaltenen Theilen in ihrer Form erbalten; in den nekrotischen sind sie kurz, geschlängelt und aufgetrieben.

V) 50 h. p. m. 6 d. p. op. negativ.

Dem am 28. Mai 1897 Morgens $7 \mathrm{Jbr}$ (cf. no I, II und IV) getödteten, etwa 6 Wocben alten Kaninchen wird am 30. Mai 1897 morgens $10 \mathrm{Ubr}$, also 50 Stunden nach dem Tode, von der linken Tibia ein Periost- 
lappen entnommen und einem etwa $1 \mathrm{Jabr}$ alten Kaninchen zwischen die recbten Glutäen implantirt.

Am 5. Juni 1897, also 6 Tage post transplantationem, findet sich das Operationsgebiet entzündlich geschwollen. Der Periostlappen schwimmt in einem rahmigen Eiter und macht einen total nekrotischen Eindruck.

Fixation in toto in Flemming'scher Lösung.

Mikroskopisch finden sich rom transplantirten Periost nur noch die elastischen Fasern einigermaassen in längeren Zügen erbalten. Die Zellen desselben haben, ausser einigen zusammengeballten Chromatin-Klumpen, überhaupt keine Färbung mehr angenommen. Die bindegewebigen Theile sind stark gequollen und haben ein homogenes Aussehen angenommen. Zwischen ihnen, sowie dem ganzen Periostlappen liegen reichliche Massen von Eiterkörperchen.

Zusammenfassung: Ein 50 Stunden nach der Tödtung des Kaninchen entnommenes und transplantirtes Perioststück ist am 6. Tage durch Eiterung völlig nekrotisirt.

VI) 56 h. p. m. 28 d. p. op. negativ.

Einem am 9. Juni 1897 Morgens $10 \mathrm{Uhr}$ getödteten Kaninchen (aus dem Wurf von No. I) wird am 11. Juni Nachmittags 6 Dhr, also 56 Stunden nach der Tödtung, ein Periostlappen vom linken Radius entnommen und einem etwa $\frac{1}{2}$ Jahre alten Thiere $z$ wischen die Musculatur des linken Oberarms transplantirt.

Am 28. Tage post transplantationem findet sich nur ein minimaler, dünner, bindegewebiger Rest des Periosts an der Implantationsstelle vor; von irgend welcher Proliferation ist nicht die Rede.

Zusammenfassung: Ein 56 Stunden post mortem transplantirter Periostlappen ist am 28. Tage post transplantationem der Resorption anheimgefallen.

VII) 56 h. p. m. 28 d. p. op. negativ.

Demselben Thiere, wie No. VI, wird ebenfalls 56 h. post mortem ein Periostlappen von dem rechten Radius entnommen und bei einem etwa $\frac{1}{2}$ Jahre alten Kaninchen zwischen die Musculatur des linken Oberarms transplantirt. Bei der Fixation des Lappens durch Nähte rollt sich derselbe stark zusammen und lässt sich nicht mebr gut ausbreiten.

Am 28. Tage post transplantationem findet sich ebenfalls nur ein dünner, bindegewebiger Rest vom Periost vor.

Zusammenfassung: Ein 56 Stunden post mortem transplantirter Periostlappen, der sich stark aufgerollt hatte, ist am 28. Tage post transplantationem bindegewebig degenerirt.

VIII) 74 h. p. m. 28 d. p. op. positiv (Figur 2).

Am 9. Juni 1897 Morgens 10 Uhr wird ein etwa 3 Monate altes Kaninchen getödtet und ihm am 12. Juni 1897 Mittags, also 74 Stunden 
post mortem ein Periostlappen von einer Tibia entnommen und bei einem etwa $\frac{1}{2}$ Jahre alten Tbiere zwischen die Musculatur des Oberschenkels transplantirt.

Am 28. Tage post operationem findet sich fest verwachsen mit dem unterliegenden Muskel ein mandelförmiger Knochenkern. Derselbe hat die ansehnliche Grösse von $1,5 \mathrm{~cm}$ in der Länge, $1 \mathrm{~cm}$ in der Breite und 2 min in der Dicke.

Das Aussehen ist völlig das eines Knochens; die Consistenz ist knoehenbart durch eingelagerte Kalksalze, so dass zur Herstellung eines Durchschnittes zur Säge gegriffen werden muss. Auf diesen Schnitt sieht die Peripherie mebr zusammenhängend, compacter aus, während das Centrum ein etwas spongiöses Ausseben zeigt.

Nach den Rāndern zu flacht sich der Kriochenkern ab und geht allmählich in die peripherischen Theile des transplantirten Periostlappens über, welcher bier das Aussehen von derbem, fibrösem Gewebe hat und keine Wucherung erkennen lăsst.

Zur mikropischen Untersuchung wird die eine Hãlfte des Präparats in Müller'scher Flüssigkeit, die andere in Alkobol und Pikrinsäure entkalkt und gehärtet. Färbung nach den verschiedenen angegebenen Methoden.

Der etwa $1,5 \mathrm{~cm}$ lange und etwa 2 mia breite Schnitt zeigt bei schwacher Vergrösserung an der einen (linken) Seite eine schmale Schicht von Muskelgewebe (a); auf dieser lagert, verbunden durch ein kernreiches Bindegewebe, die FibroElastica des transplantirten Periosts, kenntlich bei Orceinfärbang an ibrer nur an einzelnen Stellen unterbrochenen dicken Scbicbt von elastischen Fasern. Diese liegen wie ein Wall zwischen dem Muskel- und dem ProliferationsProdukt des Periosts, einer etwa $7 \mathrm{~mm}$ langen und $1,2 \mathrm{~mm}$ breiten, an beiden Enden abgerundeten Schicht von Knorpel-Knochengewebe.

Die Structur desselben ist äusserst abwechslungsreich.

An dem oberen $\mathrm{Pol}$ des Ovals findet sich in der ganzen Breite ein dem osteoiden sebr ähnliches Gewebe. Zierliche Bälkchen erbeben sich von der ursprünglichen Periostsehicht, sie sind unterbrochen von typischen Markräumen, die mit Markgewebe erfüllt sind.

Die Grundsubstanz dieser Balken ist homogen und färbt sich intensir mit Carmin ${ }^{1}$ ). Die Zellen, welche sich darin finden, sind richtige Knorpelzellen. Diese Form, welche auch Krafft bei seinen Untersuchungen des Callus beschrieben hat, ist von Kassowitz ${ }^{2}$ ) als chondroide Modification des osteoiden Gewebes bezeichnet worden.

Dieses chondroide Gewebe (ch) zieht sich nun, wenn auch lange nicht in der eben beschriebenen Mächtigkeit, an der der Fibrio-Elastica entsprechenden Seite herunter, ein Stäckehen auch an der entgegengesetzten Seite. Dann geht es allmählich, besonders zum Centrum hin, ohne scharfe

3) Wegen des besseren Contrastes ist in der Abbildung No. I nur eine Färbung mit Hämatoxylin-Eosin wiedergegeben.

2) Kassowitz: a. a. 0 . 
Grenze in richtigen hyalinen Knorpel ( $\mathrm{hk}$ ) oder auch in einen Zellknorpel (zk) über, der dem embryonalsten Typus entsprechend nur ganz dünne Septa als Grenzen der einzelnen Zellen besitzt. Das Bild, das hier nun durch die Retraction des Protoplama der Zellen entsteht, gleicht dem Durchschnitte einer Bienenwabe. In jedem Hoblraum liegt eine Zelle mit einem Kern, oft aber auch mit zwei, zuweilen auch drei Tochterkernen.

In den Markräumen des chondroiden Gewebes finden sich nun typisches Mark (r), sowie grössere und kleinere Blutgefässe (b). Diese sieht man auch in den hyalinen und den Zell-Knorpel eindringen. Zahlreiche grosse Zellen, anscheinend noch von der Keimschicht stammend, begleiten sie, und man kann beobachten, wie die Grundsubstanz am byalinen und am Zell-Knorpel in der Nähe der Gefässe blasser tingirt ist, dann schwindet, die Zellen frei werden und sich anscheinend dem sich bildenden Markgewebe anschliessen.

Wo und wann der Resorptions-Prozess Halt macht, ist nicht festzustellen; dass er aber thatsächlich aufhört, erscheint mir nach der Struktur der chondroiden Bälkchen sicher, da diese aus dem anscheinend zuerst gebildeten byalinen und Zell-Knorpel bestehen bleiben, wie man an ibrem directen, innigen Zusammenhange seben kann. So besteht diese Zellwucherung und Absorption besonders an der Grenze des oberen Drittels, welehes ganz von chondroiden Bälkchen eingenommen ist, zum mittleren, wo die beschriebenen Uebergänge deutlich zu erkennen sind.

Nicbt unerwähnt soll bleiben, dass in dem oberen Drittel Bälkchen sich finden, deren Kerne gar keine oder nur sebr schwache Fărbuug angenommen haben. Ob hier ein Zugrundegehen oder Absterben der neugebildeten Massen vorliegt, ist nach den histologischen Befunden allein nicht zu sagen.

Die elastischen Fasern sind in diesem Präparat, wie erwähnt, stellenweise besonders mächtig vertreten, und zwar ist es die $0,1 \mathrm{~mm}$ dicke Schicht der Fibro-Elastica des transplantirten Periosts, welche in ausgesprochener Weise der langen Knorpel-Knocheninsel - ungefäbr in der Hälfte ibres Verlaufes im. Schnitte - zur Grundlage dient. Dann setzt sie scharf $a b$ und verschwindet in der T'iefe, als ob sie in eine andere Ebene - vielleicht dureh Faltung oder Zusammenziehung des Periostlappens übergehe. Die einzelnen elastischen Fasern sind ganz lang und sehwach gewellt. Nur an dem oberen, ovalen Ende des chondroiden Gewebes ist eine schleifenförmige Figur entstanden durch Faltung des bei der Proliferation sich nieht mehr betheiligenden, bindegewebig degenerirten Periosts, wo die Fasern stärker gewellt sind und zu Knäueln geballt liegen.

Die Faserschicht unter dem chondroiden Gewebe zieht sich nun in einzelnen Theilen scharf von demselben abgegrenzt hin, dann kommen aber Partien, besonders wo sich ein Markraum oder ein Gefäss von der Periostlage einsenkt, wo die Faserzäge mit in das chondroide Gewebe eintreten und sich in demselben verbreiten. (v) Wir finden die Fasern nun sowohl in den Bälkchen, als auch in dem byalinen und Zell-Knorpel, be- 
sonders in letzteren beiden. Meist sind es einzelne Fasern, oft aucb mehrere zusammen, welche fast regelmässig parallel zur Periostrichtnng verlaufen, bald in Jangen Zügen, bald aus der Tiefe aus einer anderen Ebene auftauchend und dann wieder verschwindend.

Zusammenfassung: Ein Periostlappen, 74 Stunden nach Tödtung des Thieres entnommen und transplantirt, hat bis zum 28. Tage post transplantationem ein bedeutendes Proliferations-Produkt in Gestalt eines $1,5 \mathrm{~cm}$ langen, $1 \mathrm{~cm}$ breiten, $2 \mathrm{~mm}$ dicken Knochenkernes geliefert.

Histologisch setzt derselbe sich zusammen aus einer $2 \mathrm{~mm}$ breiten Zone chondroiden Gewebes, mit Bälkchen und Markraumbildung, welchem sich hyaliner und Netz-Knorpel anschliessen. In beiden letzteren Geweben finden wir Umwandlangs-Vorgänge zur chondroiden Substanz.

Elastische Fasern finden sich sowohl in allen Gewebsarten eingelagert, wie auch in der transplantirten Fibro-Elastica des Periosts in ursprünglicher mächtiger Ausdehnung.

IX) 100 h. p. m.; 12 d. p. op. positiv.

Am 14. Juli 1897 morgens $8 \mathrm{Chr}$ wurde ein etwa drei Monate altes Kaninchen getötet und ihm am 18. Juli 1897 mittags $12 \mathrm{Ubr}$, oder $4 \mathrm{~T}$ age +4 Stunden $=100 \mathrm{Stunden} \mathrm{nach} \mathrm{der} \mathrm{Tödtng,} \mathrm{ein} \mathrm{Periostlappen}$ von der Tibia entnommen und bei einem ebenso alten Thier (von demselben Wurf) zwischen die Musculatur eines Oberschenkels transplantirt.

Am 30. Juli 1897, also 12 Tage post transplantationem, starb das Thier. Nach Freipräparirung findet sich das implantirte Periost als ein $1 \frac{1}{2} \mathrm{~cm}$ langer, tanbenfederkiel-dicker Strang, der ungefähr in der Mitte etwas eingezogen ist. Das abwärts hiervon gelegene Gewebe sieht bindegewebig derb aus, während das darüber gelegene knollig verdickt, durch Kalksalze völlig hart und nach Aussehen und Consistenz normalem Knochengewebe entspricht, und zwar in einer Länge von $7 \mathrm{~mm}$ und Breite von $3 \mathrm{~mm}$. Diese Massen gehen in ziemlich scharfem Abfall über in eine dünne, bindegewebige Schicht, welche die Randtheile des Periosts darstellt. Das Stück wird in toto in Müller'scher Flüssigkeit conservirt.

Die mikroskopische Untersuchung des Längsschnittes senkrecht zum Periost ergiebt, dass das Proliferations-Prodult des transplantirten Periosts eine $7 \mathrm{~mm}$ lange und $0,6-1,0 \mathrm{~mm}$ breite Wucherungszone von osteoidem Gewebe ist, dessen eines Ende in hyalinen Knorpel übergeht.

Des Weiteren sehen wir, dass das Periost mit dem unterliegenden Muskel durch lockeres Bindegewebe verbunden ist, welches ron zablreichen, z. Th. sehr voluminösen Gefässen durchzogen wird. Scharf hebt sich hiervon, ähnlich wie im vorhergehenden Fall No. VIII, (bes. bei Orceinfärbung) die 
bis $0,03 \mathrm{~mm}$ breite Fibro-Elastica durch ibre elastischen Fasern ab. Hieran schliessen sich die Bälkchen der osteoiden $S$ ubstanz mit deutlich ausgesprochenen Knochenkörperchen.

Die Metaplasie der Knochenkörperchon aus den Knorpelzellen ist in geradezu ausgezeichneter Weise an dem Uebergang des osteoiden Gewebes zu der 1,20 mm langen und $1 \mathrm{~mm}$ breiten Knorpelmasse erkennbar. Diese besteht hauptsächlich aus Netzknorpel, deren Zwischensubstanz, wie schon früher geschildert, ein minimal dünnes maschiges Netzwerk bildet.

Die Zwischensubstanz wird dicker und nimmt allmählich eine intensivere Färbung an, dadurch erscbeinen die Knorpelzellen in mehr geordneten Reihen gelagert. Dazwischen wuchern aus dem Markgewebe, in dessen Răumen an diesem Grenzstadium ein besonderer Gefässreichtum berrscht, feine Gefässe. Dieselben scheinen mir oft begleitet von osteoblastischen Zellen des Keimgewebes, welches in den Markräumen sich häufig zeigt. Dann aber findet auch eine Auflösung der Zwischensubstanz des Knorpelgewebes statt und die dadurch frei gewordenen Knorpelzellen betheiligen sich an der Markgewebe-Bildung. Die Knorpelzellen, welche in den Balken, die wir als "chondroides" Gewebe bezeichnen müssen, sich finden, verlieren weiterhin den ausgesprochen scharfen, runden Rand ibrer Kapsel. Derselbe wird unregelmässig, zackig und schliesslich haben wir, entstanden aus dieser metaplastischen Zone, ausgesprochene Knochenkörperehen.

Ein weiterer Unterschied zwischen dem Knorpel- und Knochengewebe besteht in ihrem Verhalten zur Matrix, dem Periost. Bei ersterer kann man die allmähliche Bildung aus der osteoblastischen Schicht, wie es ähnlich in No.I-III gesehildert ist, in der sehrittweisen Ausbildung der Zellen beobachten, só dass keine Grenze irgendwie zu ziehen ist. Anders bei der völlig ausgebildeten osteoiden Substanz. Die Knochengrundsubstanz setzt sich natürlich scharf ab gegen das relativ zellarme Gewebe des Periosts, mit dem sie in losem Zusammenhang stebt. An vielen Stellen scheint die osteoblastische Schicht völlig verbraucht. Nur dort, wo sich ein Markraum zur Periostseite öfnet, sind noch Osteoblasten vorbanden, welche, in Zügen in denselben umbiegend, sich mit dem Markgewebe vermischen.

In ganz derselben Weise verhalten sich auch die elastischen Fasern. Den bis $0,03 \mathrm{~mm}$ breiten Saum derselben habe ich schon geschildert. An der Knorpel-Insel vertheilen sich die Fasern, z. T. wie durch die Wucherung auseinandergedrängt, durch fast die ganze Breite, oft auch von unten auftauchend. In der eigentlich metaplastischen Zone zur osteoiden Substanz sieht man hie und da noch eine und die andere Faser. Ist die Metaplasie aber völlig eingetreten, so hört ihr Vorkommen ganz auf. Ebenso zieht die Fibro-Elastica unter den spongiösen Bildungen scharf hin; nur an den zu ibr geöffneten Markräumen ziehen einige Fasern hinein, ohne sich jedoch weiter darin zu verbreiten.

Zusammenfassung: Ein Periostlappen, 100 Stunden nach Tödtung des Kaninchens entnommen und auf ein Thier 
(desselben Wurfes) transplantirt, hat bis zum 12. Tage post transplantationem eine ausgedehnte Knorpel-und Knochenw ucherung gezeitigt, in einer Länge von $7 \mathrm{~mm}$ und Breite von $1 \mathrm{~mm}$ im mikroskopischen Schnitt.

Die Knorpelzone, welche besonders aus Zellknorpel besteht, macht eine Metaplasie durch zu chondroidem und osteoidem Gewebe, deren Uebergangsformen in schönster Weise vertreten sind.

Die elastischen Fasern der transplantirten Fibro-Elastica sind ausgezeichnet in breitem Bande erhalten und fächerartig in der Knorpelzone ausgebreitet. In der osteoiden Substanz finden sie sich garnicht, abgesehen von einigen benachbarten Markräumen, in welche sie von der Fibro-Elastica aus gemeinsam mit den Osteoblasten hineinragen.

X) 100 h. p. m. : 13 d. p. op. positiv.

Von dem am 14. Juli 1897 morgens 8 Uhr getödteten Kaninchen (vgl. No. IX) wird am 18. Juli 12 Uhr Mittags, also $4 \times 24+4=100$ Stunden nach der Tödtung, ein Periostlappen von der einen Tibia entnommen und bei einem ebenso alten Thier (von demselben Wurf) zwisehen die Musculatur des Oberschenkels transplantirt.

Am 13. Tage nach der Operation konnte man sehon durch die Haut einen kirschengrossen, harten Knoten fühlen. Nach der Eröffnung der Implantationstelle fand sich ein $1,5 \mathrm{~cm}$ langes, ebenso breites und $7 \mathrm{~cm}$ dickes, durch Kalksalze völlig bartes Knochenstück vor, welches, von derberen, bindegewebigen Partien umgeben, mit den Muskeln der Nachbarschaft verbunden war.

Das in Müller'scher Flüssigkeit fixirte und entkalkte Präparat lieferte folgende mikroskopischen Bilder:

Das ganze Gewebe des eben geschilderten Knotens setzt sich in seiner Hauptsache in einer Mächtigkeit von $1 \mathrm{~cm}$ Länge und $4 \mathrm{~mm}$ Breite in Ovalärform zusammen aus hyalinem Knorpel, welcher an einzelnen Stellen von einfachem Zellenknorpel durchsetzt ist. An der Seite des Ovals, welche der Fibro-Elastica des transplantirten Periosts, - kenntlich an der Schicht von elastischen Fasern, die hier allerdings lange nicht in der Mächtigkeit, wie im vorhergehenden Falle, entwickelt sind - entspricht, ist auch hier eine $5 \mathrm{~mm}$ lange and $1 \mathrm{~mm}$ hohe Partie von osteoidem Ge w ebe entstanden, dessen zierliche Bälkchen mit dem Knochenkörper allmählich in den Knorpel, speciell den Zellknorpel, übergehen. Auf die Beschreibung dieser Gewebe und seiner Genese will ich bier nicht nochmal im Einzelnen eingehen, da beim vorhergehenden Fall dies schon in ausführlicher $W$ eise geschehen ist.

Hier seien aber noch zwei Punkte erwähnt: einmal die nähere Umgebung 
der Knorpelknocheninsel, dann der Reichtum an Gefässen, welcher hier zu beobachten ist.

Die Verbindung mit dem unterliegenden Muskel ist, wie früber auch, durch lockeres Bindegewebe erfolgt. An der einen Seite hat sich aber das Periost nach oben umgesehlagen, wie eine Muschelschale um ihren Inbalt. Dabei ist es aber z. Th. zu Grunde gegangen. Beide Prozesse können mit bedingt sein durch die Nabt, welche zur Fixation des transplantirten Lappens diente und hier in der Nähe durch den Schnitt getroffen ist. Die ganze Partie ist von einer grossen Zahl von Rundzellen eingenommen; dazwischen namentlich an den Stellen, wo die Seitenreste liegen, finden sich auch Riesenzellen. Die elastiscben Fasern des Periosts sind ganz kurz zusammengeballt, zum grösten Theil schon körnig zerfallen.

Eine $z$ weite Seidennaht findet sich am unteren Pol des Knorpelovals, und $z$ war direct auf dem hyalinen Knorpel aufliegend, so dass die Zellwucherung um die'Seidenreste die Umgebung soweit hineinbezogen hat, dass an dem Knorpel eine Entwickelung derselben stattgefunden hat.

Des Weiteren nimmt der Kernreicbthum allmäblich ab, so dass die Knorpelwueherung nach aussen hin von einem zellreichen Gewebe bedeckt ist, welches in den dem Knorpel näheren Schichten den Typus des Bindegewebes hat, während in den ferner liegenden Partien ein ausgesprochen myxomatöser Charakter vorwiegt.

In diesen Bezirken, besonders aber ì den erstgenanuten, findet sich nun eine zahlreiche Bildung von jungen Gefässen. Dicht auf dem Knorpel zieht sich eine solche Lage, ansgekleidet ron einem niederen Endothel in ziemlicher Ausdehnung bin. Aber auch in dem Knorpel selbst sind zahlreiche feinste und auch grössere Gefässe, deren Umgebung gröstentheils sebr zellreich ist, so dass von der Knorpelstruktur wenig oder gar nichts zu erkennen ist. Aebnliche Bilder bei der Bildung der chondroiden Bälkchen sind schon früber beschrieben. Hier hat man aber oft den Eindruck, als ob es sich nicht nur lediglich um Factoren handele, welche eine weitere metaplastische Umbildung bewirkten, sondern um degenerative, destructive Prozesse.

Von dem Zugrundegehen der elastischen Fasern an dem bei der Proliferation nicht betheiligten Theil des Periosts habe ich schon gesprocben. An den proliferirten Partien sind die Fasern der Fibro-Elastica gut erbalten, oben nur an einzelnen Stellen, und das auch nur in beschränkter Anzahl in Bündeln von feinen, langen Fasern. Vornehmlich ist dies der Fall dort, wo der hyaline Knorpel der Fibro-Elastica direct aufliegt, während beim Beginn der osteoiden Bälkchenbildung die Fasern sich fächerförmig theilen und durch die Knochengrundsubstanz in breiter Zone bindurchziehen. Im directen Gegensatz zum vorherbeschriebenen Präparat No. IX steht also hier das Verhalten der elastischen Fasern. Wobl aber sind dieselben in der grossen Knorpelinsel auch zablreich vertreten.

Zusammenfassung: Ein Periostlappen, 100 Stunden nach der Tödtung, also am 5. Tage entnommen und 
auf ein Kaninchen (desselben Wurfes) transplantirt, zeigte am 13. Tage als Proliferations-Produkt einen haselnussgrossen $1,5 \mathrm{~cm}$ langen, $1,5 \mathrm{~cm}$ breiten und $7 \mathrm{~mm}$ dicken Knochen. Mikroskopisch setzt derselbe sich zusammen aus Zellknorpel, hyalinem Knorpel and osteoidem Gewebe.

Eine reichliche Gefässneabildung hat in und um den Knochen stattgefunden.

Elastische Fasern finden sich in der Fibro-Elastica des transplantirten Periosts, den Knochenbalken der osteoiden Substanz und dem hyalinen und Zell-Knorpel.

Eine weitere Reihe von Versuchen mit Transplantationen 117 and 124 Stunden nach der Tödtung habe ich noch vorgenommen. An einigen Stellen glaube ich in den mikroskopischen Präparaten Bilder gesehen zu haben, welche auch hier noch eine erhaltene Proliferations-Fähigkeit za zeigen schienen. Da mir dieselben indessen nicht ganz überzeugend und weit entfernt von den oben beschriebenen Befunden waren, so zog ich es vor, dieselben hier nicht weiter $z u$ beschreiben. Leider waren es äussere Umstände, welche mich seiner Zeit vorläufig von einer weiteren Fortführung der Versuche abhielten. Die ausgezeichnet erhaltene Proliferations-Fähigkeit noch am 5. Tage post mortem, glaube ich, berechtigt mich wohl zu der Annahme, dass noch länger die Vitalität der Periostzellen bestehen kann, und hoffe ich, dass ich vielleicht später in der Lage sein werde, weitere Erfahrungen darüber mitzutheilen.

Dass nicht alle Versuche geglückt sind, darf nicht Wunder nehmen. Es spielen zu viele Factoren mit in der Angelegenheit, deren störende Wirkung auch schon Ollier in seinen Versuchsreihen kennen lernen musste. Zur richtigen Würdigung der von mir erzielten positiven Ergebnisse ist es nothwendig, auch einmal das Zahlenverhältniss zwischen Erfolgen und Misserfolgen bei solchen Versuchen, bei denen sofort nach der Entnahme die lebenswarmen Gewebe überpflanzt worden sind, zum Vergleiche heranzuziehen.

Bruns ${ }^{1}$ ) hat bei seinen Transplantationen von Knochenmark lange Zeit mit Misserfolgen zu kämpfen gehabt. Es miss-

1) P. Bruns: Ueber Transplantationen von Knochenmark. Areh. f. klin. Chir. Bd. 26. 
langen ihm 66 Versuche, bei denen er Knochenmark von einem Thiere entnahm and einem anderen implantirte. Erst als er die Bedingungen für das Fortleben der freipräparirten Knochenmarkstücke auf das allergünstigste gestaltete, indem er letztere demselben Thier, dem sie entnommen, unter die Haut verbrachte, sie also der Ernährung mit demselben Blate, wie bisher, zurückgegeben warden, erzielte er Erfolge. Aber auch diese waren in der Zahl beschränkt, denn von 19 derart vorgenommenen Versuchen gelangen nur 12.

Bei den Katzen, welche ich zuerst - mehr durch Zufall veranlasst - benutzte, mögen besonders die Ernährungs - und Pflegeverhältnisse eine Rolle spielen, da eine Stallgefangenschaft ihrem Charakter am wenigstens entspricht.

Bei den Meerschweinchen glaube ich als besonderen Grund des Misslingens die ausserordentliche Schwierigkeit anführen zu können, welche das Operationsmaterial bietet. Das abzulösende Periost ist bei denselben oft von einer Feinheit, wie Spinnengewebe. So ist es sehr wahrscheinlich, dass selten oder nie die für uns in Betracht kommende osteoplastische Schicht in genügender Weise zur Transplantation conservirt war. Ebensowenig war es aber auch immer möglich, die difficilen Periostlappen bei der Transplantation schön auszubreiten und zu fixiren. Auch bei den Meerschweinchen kam winterliche Stallfütterung dazu.

Bei Kaninchen habe ich im Ganzen 18 Transplantationen vorgenommen. Unter diesen 18 sind 7 erfolgreich verlaufen.

Bei Durchsicht der Protocolle findet man, dass unter den 7 wohlgelungenen Operationen 4 sind, bei denen die Transplantation von einem Thier auf ein Geschwisterthier desselben Wurfes gemacht worden ist. Offenbar ist dieser Umstand von Einfluss, wie die Protocolle der Experimente II, III, IX und $\mathrm{X}$ ergeben, welche über die Hälfte der gelungenen Versuche darstellen.

Am deutlichsten tritt dieser Einfluss an den beiden letzten Versuchen IX und X hervor; denn obgleich hier die grössten Anforderungen an die Erholungsfähigkeit der Gewebe gestellt waren, so übertrifft der Erfolg bei ihnen doch bei weitem die Befunde bei anderen Versuchen von viel kürzerer Dauer. 
Im Fall II hat unter diesen günstigen Bedingungen schon eine Bildung von osteoidem Gewebe stattgefunden, was in einem derselben Zeit entsprechenden anderen Versuch noch nicht der Fall war. Die Zahl meiner Beobachtungen ist zu einem Schluss auch zu klein. Einen Misserfolg bei allen den zwischen Verwandten vorgenommenen Transplantationen habe ich aber überhaupt nichtzu verzeichnen, so dass es ein Wink für spätere Versuche sein dürfte.

Was nun die gelungenen Versuche beim Kaninchen betrifft, so haben wir gesehen, dass es noch weit über Ollier's Angaben hinaus gelingt, Knochenbildung an transplantirtem. Periost längere Zeit schon todter Thiere zu beobachten.

Wie aus den Operationsberichten ersichtlich, erzielte ich nach:

$\begin{array}{rcccl}29 & \text { Stunden } & \text { post mortem } & \text { (No. I und II) } \\ 48 & - & - & - & \text { (No. III) } \\ 50 & - & - & - & \text { (No. IV) } \\ 74 & - & - & - & \text { (No. VII) } \\ 100 & - & - & - & \text { (No. IX und X) }\end{array}$

die treffendsten Belege, dass das transplantirte Periost seine volle Proliferations-Fähigkeit bewahrt hat, indem es typische Bilder von Knorpel- und Knochengewebe producirte.

Was die Art und Weise der Proliferations-Vorgänge des Periosts betrifft, so haben wir gesehen, dass dieselben dem sonstigen Verhalten des Periosts bei Wachsthums- oder Regenerationsprozessen entspricht. Auf die Wichtigkeit der osteoblastischen Schicht bei diesen habe ich schon wiederholt hingewiesen.

Da nun die osteoblastische Keimschicht ein Ueberbleibsel specifisch modificirten, embryonalen Bindegewebes, des chondrostealen Blastems ist, so ist es natürlich, dass bei allen Wucherungs-Vorgängen es sich mehr oder weniger an den embryonalen Typus anlehnt, wie es beim Callus auch der Fall ist. Beim Menschen ist hierbei allerdings die directe Verknöcherung des periostealen Bildungsgewebes (ausgenommen etwa bei kleinen Kindern) die Regel; bei den gewöhnlichen Versuchsthieren, so dem Hund und Kaninchen, besteht nach Bruns ${ }^{1}$ ) aber zuerst der Callus grösstentheils aus Knorpel, welcher später verknöchert. Dieser soll nicht identisch sein mit dem gewöhnlichen Hyalin-

1) P. Bruns: Die Lehre von den Knochenbrüchen. Deutsche Chirurgie (Billroth und Lücke). Lfg. 27. 1886. S. 204. 
knorpel, da Bruns seinen Uebergang in Knochen durch einfache Metaplasie beobachtete, was bei den von mir beschriebenen Periost-Wucherungen (z. B. bei No. IX) auch zu constatiren war.

Dass gerade unter den besonderen Bedingungen, welchen meine Periostpräparate unterworfen waren, auch atypische Wucherungen eine grössere Rolle spielen, ist wohl leicht anzunehmen.

Die Anordnung meiner Versuche zielte zwar nicht hin auf den zeitlichen Entwickelungs-Modus, aber ich will hier in Kürze in zeitlicher Folge die gelieferten Bilder ordnen.

Nach der Transplantation finden sich:

Am 3. Tage (No. III) zeigt ein 48 Stunden alter Periostlappen die ersten Zeichen einer Proliferation in Gestalt von zahlreichen Mitosen in der osteoblastischen Schicht.

Am 6. Tage (No. IV) sind die osteoblastischen Zellen eines 50 Stunden alten Lappens in ihrer Differencirung bedeutend weiter. Dieselben haben an Grösse und Polymorphie zugenommen und zeigen schon den Typus der Knorpelzellen.

Am 7. Tage (No. I) hat ein 29 Stunden conservirter Periostlappen eine grössere Wucherung hyalinartigen Kn orpels produ- . cirt; Keimschicht, wie Fibro-Elastica, zeigen Zell-Vergrösserungen und mitotische Theilung. Die elastischen Fasern sind auseinandergedrängt und durchziehen stellenweise den neugebildeten Knorpel.

Ebenfalls am 7. Tage (No.II) hat ein 29 Stunden conservirter (dann auf ein Thier desselben Wurfes transplantirter) Lappen schon eine ansehnliche Insel osteoider Substanz gebildet. In einen Markraum derselben zieht ein Zug elastischer Fasern mit den Osteoblasten hinein, während die übrigen Fasern auseinandergedrängt sind.

Am 12. Tage (No. IX) sehen wir als Erfolg der Proliferation eines 100 Stunden alten Lappens bei einem Thiere desselben Wurfes eine reichliche Knorpelzone, theils aus hyalinem, meist aus Zellknorpel bestehend, welche sich gradatim in chondroides und osteoides Gewebe umwandelt. Unter letzterem ziehen die elastischen Fasern hin und breiten sich fächerförmig in dem Knorpelknoten aus.

Am 13. Tage (No. X) hat ein ebenfalls 100 Stunden conservirter Periostlappen einen haselnussgrossen Knochen gebildet, 
welcher aus Zellknorpel, hyalinem Knorpel und osteoidem Gewebe besteht. Elastische Fasern finden sich sowohl in dem Knorpel, wie auch in den Balken des osteoiden Gewebes. Reichliche Gefässneubildung hat in und um die Neubildung stattgefunden.

Am 28. Tage (No. VIII) ist das Endprodukt eines 74 Stunden post mortem transplantirten Lappens auch ein bedeutendes Gebilde, aus hyalinem Netzknorpel and chondroidem Gewebe bestehend, in denen elastische Fasern eingelagert sind.

Wir sehen aber, wie sich Schritt für Schritt, aus dem Periost die Bildung von hyalinem, bezw. Zell-Knorpel, chondrọidem und osteoidem Gewebe verfolgen lässt - ProliferationsVorgänge, welche, wie aus den Präparaten hervorgeht, durch einen zellenfreien Saftstrom bewirkt werden.

Eine besondere Erwähnung verdienen noch die elastischen Fasern.

Während nehmlich, wie erwähnt, Bonnet bei Neugeborenen in der osteoblastischen Schicht und im Knochen derselben überhaupt keine Fasern gefunden hat und ihr späteres Vorkommen auf Zug- und Druckkräfte zurückführt, sehen wir in unseren Präparaten ein Hineinziehen der elastischen Fasern in die Wucherung von Anbeginn an. Obgleich wir nun hier von einer physiologischen Inanspruchnahme der Neubildungen kaum reden köunen, - es sei höchstens der Druck der Muskeln, zwischen welche das Periost transplantirt wurde - so sehen wir die Fasern nicht nur im Knorpel, sondern auch in der chondroiden und osteoiden Substanz auftreten und bestehen.

Ueber das spätere Schicksal transplantirter Gewebsstücke liegen Mittheilungen vor, welche, biologisch betrachtet, sehr verschiedenen Gruppen angehören.

Einmal fand Barth ${ }^{1}$, dass Knochenstücke, welche vorher geglüht waren, der Resorption anheimfielen und dass dabei anscheinend durch einen eigenartigen Chemismus eine Anregung von Bindegewebszellen zur Ossification erfolgte. Vorher hatte er schon, im Gegensatz zu früheren Autoren, nachgewiesen ${ }^{2}$ ), dass

1) Barth: Ziegler's Beitr. z. path. Anat, Bd. 17. 1895. S. 127, und Berliner klin. Wochschr. 33. Jahrg. 1896: Ueber künstliche Erzeugung von Knochengewebe und über die Ziele der Osteoplastik.

2) Barth: Langenbecks Arch. Bd. 46 u. 48. Ziegler's Beitr. Bd. 17. Berl. klin. Wochschr. 1894. 
transplantirte Knochen allmählich ganz zu Grunde gehen und durch neugebildeten Knochen substituirt werden.

Diese Bedingungen sind von denen meiner Versuche grundverschieden. Alle progressiven Vorgänge, welche ich beobachtet habe, konnten mit Sicherheit auf active Veränderungen der Zellen des transplantirten Periosts selbst bezogen werden. Die im Zustande herabgesetzter oder erloschener Lebensfähigkeit übertragenen Gewebsstücke übten keinerlei chemische Anregung zur Knorpel- oder Knochenbildung auf das Nachbargewebe, also hauptsächlich auf die anstossenden Muskeln aus.

Zweitens habe ich bei Uebertragung von unzweifelhaft erholungsfähigem, produktionsfähigem Periost vielfach neben neugebildetem Knorpel Stellen angetroffen, in denen die Anfänge der Zellen-Vergrösserung und Zellen-, bezw. Kern-Vermehrung eingetreten waren, in denen aber bald Fettmetamorphose anstatt mitotischer Theilung und Metaplasie zu Knorpel gefolgt war.

In diese Gruppe dürften z. Th. die von Wentscher und Enderlen beobachteten Resorptions-Vorgänge älterer transplantirter Hautlappen gehören.

Eine dritte Gruppe bilden die Vorgänge, welche an dem gewucherten und neu gebildeten Knorpel- und Knochengewebe in späterer Periode eintreten. Hierüber gestatten meine Beobachtungen kein abschliessendes Urtheil. An einigen Stellen meiner Protokolle habe ich Bilder erwähnt, welche ich mit einiger Wahrscheinlichkeit auf die Anfänge einer Einschmelzung und Aufsaugung deuten konnte; eine systematische Verfolgung dieser Vorgänge lag nicht im Plane meiner Arbeit.

Bestimmte Angaben darüber, dass in späterer Zeit die knorpeligen und knöchernen Wucherungsprodukte transplantirter Perioststücke einem gewissen Schwunde anheimfallen, finden sich bei Ollier, Cohnheim und Maass, sowie Bonome (a. a. 0.).

Die Uebereinstimmung meiner erfolgreich verlaufenen PeriostUebertragungen mit den Ergebnissen dieser früheren Beobachter lässt keinen Zweifel daran, dass die Keimschicht dieses Gewebes im Cadaver eines Kaninchens bis in den 5. Tag hinein nicht nur erholungsfähig, sondern zu derjenigen höchsten ProliferationsLeistung geeignet bleiben kann, welche man in der Wissenschaft 
als ausschliessliche Eigenschaft lebenswarm entnommener, frischer Gewebe zu betrachten gewohnt ist.

Meine Versuche beweisen aufs Neue, dass die Vita propria sich in ganz ungeahnter und daher überraschender Dauer erhalten kann, und dass es ein wissenschaftltches Postulat ist, diese Bedingungen der willkürlichen Schätzung zu entziehen und sie nunmehr durch systematische Untersuchungen vieler Gewebsarten festzustellen.

Wenn ich das lebenskräftige Fortleben des Periosts bis zu 100 Stunden, die Proliferations-Fähigkeit der Hautepithelien bis zum 22. Tage, die Motilität der Spermatozoen bis zum 11. Tage, die Erhaltung der Cilien-Bewegung der Flimmerepithelien bis zum 18. Tage als erste Ergebnisse der neueren Forschungen nach der Vita propria zusammenstelle, so dürfte P. Grawitz nicht so Unrecht haben, wenn er sagt ${ }^{1}$ ): "Vielleicht mag es noch Wochen dauern, bis das Leben in der letzten Zelle verglommen ist."

\section{Erklärung der Abbildungen. \\ Tafel XI.}

Fig. 1. (Protokoll No. I.) Vergr. 500:1. Periost von einem 23 Stunden todten Kaninchen 7 Tage nach der Transplantation. Fixation in Flemming'scher Lösung; Orcein und Saffranin. fe $=$ Fibro-Elastica des transplant. Periostes; $0=0$ osteoblastenschicht, in weleher sich $\mathrm{m}=$ Mitosen finden; $\mathrm{k}=$ Knorpelgewebe, welches sich ans 0 heraus gebildet hat; $\mathrm{e}=$ elastische Fasern in der Fibro-Elastica und der osteoblastischen Schicht. -

Fig. 2. (Protokoll No. VIII.) Vergr. 80:1. Proliferations-Produkt eines Periostlappens von einem 74. Stunden todten Kaninchen am 28. Tage nach der Transplantation. Fixation in Müller'scher Flüssigkeit; Färbung in Orcein, dann Hämatoxylin-Eosin. fe $=$ Fibro-Elastica des transplantirten Periosts; $b=$ Blutgefäss unterhalb desselben; $\mathrm{a}=$ Reste der unterliegenden Musculatur; $\mathrm{zk}=$ Zellknorpel; $\mathrm{hk}=$ hyalinartiger Knorpel; $\mathrm{ch}=$ chondroide Modification des osteoiden Gewebes; $r=$ Markräume; $v=$ Einsenken der elastischen Fasern in das Proliferations-Gewebe. -

Die elastischen Fasern sind in beiden Abbildungen durch die braune Färbung ersichtlich.

1) P. Grawitz: Deber Leben und Tod. Rectoratsrede. Greifswald. 1896. 